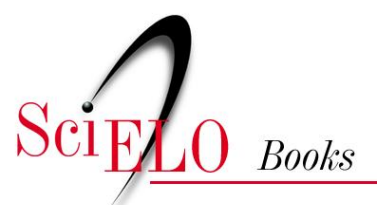

\title{
Obesidade e saúde pública
}

\author{
Luiz Antonio dos Anjos
}

\section{SciELO Books / SciELO Livros / SciELO Libros}

ANJOS, LA. Obesidade e saúde pública [online]. Rio de Janeiro: Editora FIOCRUZ, 2006. Temas em saúde collection. 100 p. ISBN 978-85-7541-344-9. Available from SciELO Books $<$ http://books.scielo.org $>$.

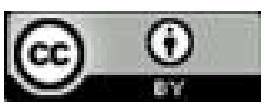

All the contents of this work, except where otherwise noted, is licensed under a Creative Commons Attribution 4.0 International license.

Todo o conteúdo deste trabalho, exceto quando houver ressalva, é publicado sob a licença Creative Commons Atribição 4.0.

Todo el contenido de esta obra, excepto donde se indique lo contrario, está bajo licencia de la licencia Creative Commons Reconocimento 4.0. 
Obesidade e Saúde Pública 


\section{FUNDAÇÃO OSWALDO CRUZ}

Presidente

Paulo Marchiori Buss

Vice-Presidente de Ensino, Informação e Comunicação

Maria do Carmo Leal

\section{EDITORA FIOCRUZ}

\section{Diretora}

Maria do Carmo Leal

Editor Executivo

João Carlos Canossa Mendes

Editores Científicos

Nísia Trindade Lima

Ricardo Ventura Santos

Conselho Editorial

Carlos E. A. CoimbraJr.

Gerson Oliveira Penna

Gilberto Hochman

Ligia Vieira da Silva

Maria Cecilia de Souza Minayo

Maria Elizabeth Lopes Moreira

Pedro Lagerblad de Oliveira

Ricardo Lourenço de Oliveira

Coleção Temas em Saúde

Editores Responsáveis

Maria do Carmo Leal

Nísia Trindade Lima

Ricardo Ventura Santos 


\section{LUIZ ANTONIO DOS ANJOS}

\section{Obesidade e Saúde Pública}

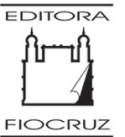


Copyright (C) 2006 do autor

Todos os direitos desta edição reservados à

FUNDAÇÃO OSWALDO CRUZ / EDITORA

ISBN: 85-7541-082-2

Capa, projeto gráfico e editoração eletrônica

Carlota Rios

Revisão

Lilia F. Gutman T. Paranhos Langhi

Supervisão Editorial

M. Cecília G. B. Moreira

Catalogação-na-fonte

Centro de Informação Científica e Tecnológica

Biblioteca da Escola Nacional de Saúde Pública Sergio Arouca

B599o Anjos, Luiz Antonio dos

Obesidade e Saúde Pública. Luiz Antonio dos Anjos. Rio de Janeiro : Editora Fiocruz, 2006.

100 p. (Coleção Temas em Saúde)

1.Obesidade-epidemiologia. 2.Saúde Pública.

I.Título.

CDD - 20.ed. - 616.398

2006

\section{EDITORA FIOCRUZ}

Av. Brasil, 4036 - Térreo - sala 112 - Manguinhos

21040-361 - Rio de Janeiro - RJ

Tels: (21) 3882-9039 / 3882-9041

Telefax: (21) 3882-9006

e-mail: editora@fiocruz.br

http://www.fiocruz.br 


\section{SUMÁRIO}

Apresentação

1. Definição de obesidade

2. Agravos à Saúde e Epidemiologia da Obesidade

3. Etiologia

4. Prevenção e Controle

Referências

Sugestões de Leituras 



\section{Apresentação}

Apesar de aceita sem muita discussão, a obesidade é definida, segundo a Organização Mundial da Saúde (OMS), como uma doença caracterizada pelo excesso de gordura corporal que traz prejuízos à saúde. Na prática clínica e em estudos epidemiológicos, porém, não se mede a gordura corporal e nem se sabe, para todos os efeitos, qual seria o limite de aceitabilidade da quantidade de gordura corporal antes que haja repercussões na saúde. De qualquer forma, a obesidade ocorre num quadro prolongado de ingestão energética maior do que o gasto energético, ou seja, balanço energético positivo.

Este livro aborda a obesidade dentro da perspectiva da saúde pública enfocando aspectos do diagnóstico, etiologia, agravos à saúde, epidemiologia e medidas de prevenção, tendo como base, sempre que possível, os dados disponíveis na população brasileira. Inicialmente, discutem-se os métodos usados para o diagnóstico da obesidade, as suas limitações e qual são as alternativas pensadas hoje para a área. Os achados dos principais estudos nacionais e regionais que avaliaram a situação epidemiológica da obesidade no Brasil são discutidos a seguir. As possíveis causas que ajudaram na construção do quadro epidemiológico no Brasil são apresentadas com a integração de dados oriundos de diversas fontes que contribuem para o entendimento da situação de balanço energético positivo na população brasileira. Por fim, discutem-se as alternativas recomenda- 
das para a prevenção da obesidade e o controle da massa corporal, dando-se ênfase aos relatos dos programas bem-sucedidos, os guias alimentares propostos para uma alimentação saudável e os problemas inerentes ao cálculo dos requerimentos energéticos na população em geral. As principais referências usadas são comentadas ao final do livro, nas sugestões de leituras; e as citadas ao longo do texto são listadas nas referências bibliográficas.

As opiniões e interpretações da literatura biomédica são fruto de trabalho do autor, acumuladas em pesquisas e estudos nos últimos 15 anos. A primeira aproximação ao tema foi ao documentar, através de um sistema de vigilância nutricional, a ocorrência de desnutrição em crianças e sobrepeso/obesidade na população adulta, particularmente, de mulheres que moravam na área de atendimento da unidade de saúde associada à Escola Nacional de Saúde Pública Sergio Arouca, da Fundação Oswaldo Cruz (Ensp-Fiocruz). Esse aparente paradoxo levou o autor a analisar os dados da Pesquisa Nacional sobre Saúde e Nutrição (PNSN) realizada em 1989 pelo extinto Instituto Nacional de Alimentação e Nutrição (Inan) e pela Fundação Instituto Brasileiro de Geografia e Estatística (IBGE).

Com uma formação acadêmica nas áreas de Nutrição e Fisiologia do Exercício, o autor passou a associar o quadro nutricional obtido em análises dos grandes inquéritos nacionais com as características ocupacionais da população brasileira nos inquéritos nacionais. Essa experiência levou à sugestão de incorporação de perguntas sobre a atividade física na Pesquisa sobre Padrões de Vida (PPV) realizada em 1997 pelo IBGE em amostra populacional dos brasileiros residentes no Nordeste e Sudeste. Paralelamente, o autor criou o Laboratório de Avaliação Nutricional e Funcional na Universidade Federal Fluminense (UFF) no qual foram desenvolvidos estudos sobre o estado nutricional, e as características de gasto energético 
em vários segmentos da população. Atualmente, o autor estuda os fatores associados à obesidade em nível familiar, na tentativa de entender o processo que leva a somente alguns membros das famílias desenvolverem o sobrepeso/obesidade.

Esse é um texto que aborda as questões relacionadas à obesidade sem a preocupação imediata de se referenciar todas as afirmações. Tentou-se apresentar o texto com todas as informações técnicas envolvidas mas da forma mais breve possível. Entretanto, foram inevitáveis, em alguns momentos, os detalhamentos técnicos que são apresentados como forma de orientação geral sobre o tema. Espera-se que o texto possa ser útil tanto para a população em geral e para os iniciantes na área quanto para os profissionais de saúde. Ao longo do livro procurou-se usar a nomenclatura correta da medida da massa corporal (em vez de peso corporal) e de energia (em vez de caloria).

Espera-se que este texto possa fazer com o que o leitor pense nas várias faces da intricada área da obesidade, principalmente num país como o Brasil que vive um período de transição e de crescimento rápido para uma sociedade cada vez mais urbana e muito desigual.

O autor agradece a generosidade da sua filha, Debora Couto Anjos, que o recebeu durante um período longo em sua casa, apesar dos seus afazeres intensos, fornecendo a infra-estrutura adequada para concentração na produção deste texto. $\mathrm{O}$ autor agradece, ainda, à Cristina Pinheiro Mendonça, Inês Rugani Ribeiro de Castro, Luciene Burlandy, Mauricio Teixeira Leite de Vasconcellos e Vivian Wahrlich que vêm contribuindo há algum tempo com o autor com discussões sobre o assunto e realização de estudos conjuntos que serviram de base para muitas das questões apresentadas neste livro. 



\section{Avaliação Antropométrica e da
Composição Corporal}

\section{DEFINIÇÃOO DE OBESIDADE}

Obesidade é definida pela Organização Mundial da Saúde (OMS) como uma doença caracterizada pelo acúmulo excessivo de gordura corporal que traz repercussões à saúde. Apesar dessa definição assumir obesidade como doença, alguns autores não consideram essa premissa como verdadeira. A definição de uma doença, do ponto de vista tradicional, requer a existência de um grupo de sinais e sintomas e alteração funcional de uma forma universal. Entretanto, como a obesidade é definida através de um valor antropométrico ou de gordura corporal acima de um ponto de corte, muitos consideram que tal procedimento, muito embora possa definir uma ameaça à saúde e longevidade, não permitiria considerar obesidade como doença. Para muitos, obesidade se comportaria mais como um fator de risco para outras doenças e não seria, por si só, uma doença. Doença ou não, a obesidade é causada por um quadro prolongado de ingestão energética maior do que gasto energético, ou seja, balanço energético positivo.

Dessa forma (doença ou só um fator de risco para outras doenças), é universal o sentimento de que seria necessário que a quantidade de gordura corporal fosse avaliada (ao que se chama de avaliação da composição corporal) quando se pensa em obesidade. Entretanto, como as técnicas acuradas de avaliação da 
composição corporal são sofisticadas e, em muitos casos caras, pesquisadores e clínicos usam medidas mais simples para identificar a obesidade. $\mathrm{Na}$ prática clínica e em estudos populacionais, utiliza-se o valor do índice de massa corporal (IMC), calculado pela divisão do valor da massa corporal (em quilogramas) pela estatura ao quadrado (em metros), também chamado de índice de Quételet em homenagem ao seu criador, como critério para se estabelecer o estado nutricional em adultos já há algum tempo, e em adolescentes e crianças mais recentemente. Este índice é usado pela facilidade de obtenção das informações de massa corporal e de estatura e pela simplicidade em ser calculado. Todavia, o IMC não representa a composição corporal dos indivíduos, ele simplesmente representa a relação entre o valor de massa corporal e a estatura.

Num passado não muito distante, o controle da massa corporal dos indivíduos era feito tendo como meta um certo valor 'alvo' ou 'ideal', que era determinado comparando-se os valores observados com as informações antropométricas de grupos populacionais, tipicamente de pessoas que realizavam seguro de saúde, consideradas como referência. Dessa forma, estabeleciamse valores de massa corporal 'ideal' segundo o valor da estatura, sem correlacionar, diretamente, com o nível de saúde desses indivíduos. De fato, o valor isolado da massa corporal não tem muito significado prático, pois dependerá da estatura do indivíduo. Portanto, qualquer relação entre o valor de massa corporal e estatura tem de ser independente da estatura para que os valores possam ser comparados entre indivíduos altos e baixos. Por isso, o IMC é o preferido já que ele apresenta correlação alta com o valor da massa corporal e correlação muito baixa com a estatura. Um problema sempre presente com o índice reside no 
fato das proporções entre a medida da perna e do tronco serem diferentes entre populações, o que pode acarretar problemas na interpretação dos resultados do IMC. Por exemplo, os indivíduos que têm pernas mais curtas poderão ter valores de IMC superiores aos dos indivíduos da mesma estatura que tenham as pernas mais compridas.

\section{AvaliaÇÃO ANTROPOMÉTRICA E DA COMPOSIÇÃO CORPORAL}

\section{Índice de Massa Corporal}

A relação entre massa corporal e estatura como forma de expressar o corpo humano já havia sido usado por Adolphe Quételet no século XIX, mas seu uso ficou esquecido até o começo da década de 1970, quando Ancel Keys e colaboradores sugeriram não só chamar a relação entre a massa corporal (em kg) dividida pelo quadrado da estatura (em m) como Índice de Massa Corporal (IMC), mas também recomendaram seu uso em estudos epidemiológicos como expressão da adiposidade humana (Keys et al., 1972). De fato, o IMC apresenta boa correlação com estimativas da composição corporal, na população em geral, particularmente com o percentual de gordura corporal (\%GC), calculado pela razão entre o valor da massa de gordura corporal (em kg) e o valor total da massa corporal (em kg) multiplicado por 100.

A boa correlação entre o IMC e o \%GC já foi documentada em várias populações no mundo e serviu como grande argumento para seu uso na avaliação da obesidade em populações. Entretanto, um mesmo valor de IMC representa valores distintos de \%GC dependo das características étnicas e ambientais da 
população ou mesmo entre homens e mulheres com o mesmo arcabouço genético. Em uma investigação, numa amostra de homens e mulheres de Palembang na Indonésia e holandeses residentes em Wageningen, constatou-se a diferença nessa relação entre populações. Apesar de a amostra da Indonésia ter, em média, menos duas unidades de IMC do que a amostra de holandeses, os indonésios tinham 3\% a mais de gordura corporal. De fato, os indonésios do mesmo gênero e com a mesma massa corporal, estatura e idade tinham $4,8 \%$ a mais de gordura corporal do que os holandeses (Gráfico 1).

Gráfico 1 - Relação entre o IMC e o \%GC de amostras de holandeses (Wageningen) e indonésios (Palembang) por gênero

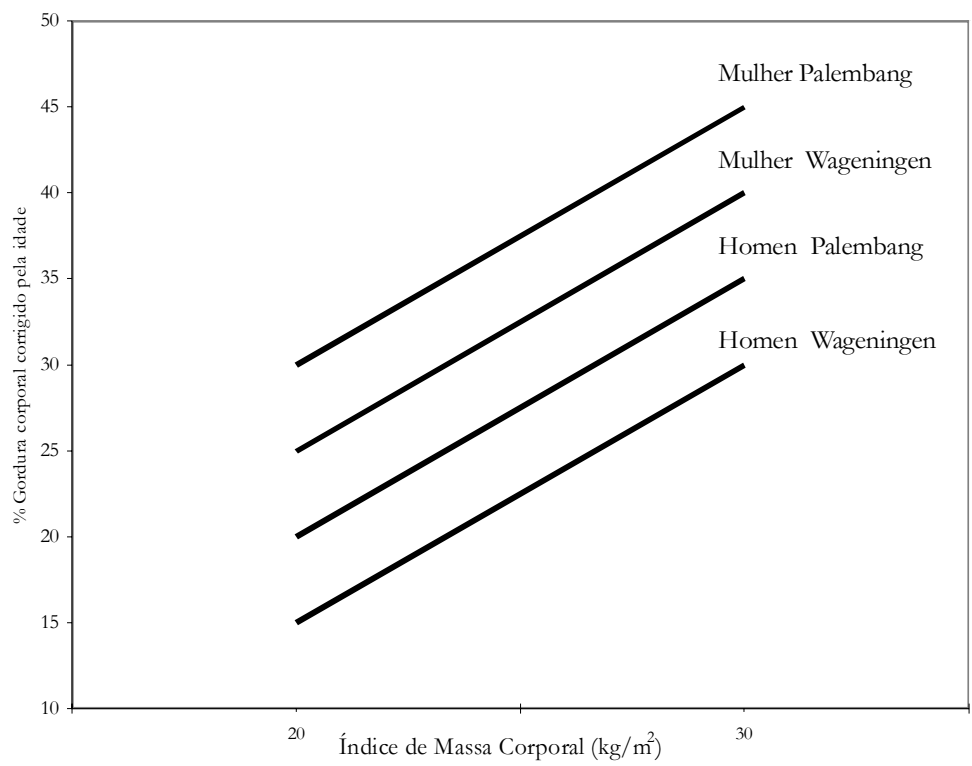

Fonte: Adaptado de Guricci et al. (1998). 
Por esses motivos, alguns autores questionam o uso universal de um único valor de IMC como critério para o diagnóstico da obesidade. No exemplo anterior, um valor de IMC igual a 30 $\mathrm{kg} / \mathrm{m}^{2}$ significa aproximadamente $30 \%$ GC para os homens holandeses (Wageningen) e 45\% GC para as mulheres indonésias (Palembang). Essas diferenças podem ser causadas por características étnicas como a constituição óssea, a relação tronco/ pernas entre outras.

\section{- Critérios para classificação do estado nutricional a partir do IMC}

Os pontos de corte para o diagnóstico nutricional em adultos vieram após o acúmulo de informações sobre a relação do IMC e as mais variadas doenças, o que levou alguns pesquisadores a sugerirem classificações de risco de adoecer baseados no IMC. A relação entre o IMC e o risco de adoecer ou morrer por determinadas doenças tem, em geral, um padrão em 'U' o que significa dizer que existe risco maior de adoecer ou morrer quando os valores de IMC são muito baixos ou muito altos e mais ou menos estáveis para valores de IMC intermediários. Nessas relações, os valores de IMC de menor risco ficam, geralmente, entre os valores de 20 e $25 \mathrm{~kg} / \mathrm{m}^{2}$. Um estudo recente realizado numa amostra grande de chineses, tendo como referência o valor de IMC entre 24 e $25 \mathrm{~kg} / \mathrm{m}^{2}$, exemplifica essa relação ao demonstrar risco relativo maior de morte por todas as causas tanto para valores mais baixos quanto mais altos de IMC (Gráfico 2). Essa relação pode também ser na forma de 'L', em lugares onde há baixa freqüência de valores altos de IMC na população, como, por exemplo, em países em desenvolvimento, ou então na forma de 'J', em lugares cuja população 
não apresenta muitos valores baixos de IMC, como encontrado nos países desenvolvidos. No Brasil, é de se imaginar que essa relação tenha a conformação em ' $U$ '.

Gráfico 2 - Relação entre o IMC e o risco de morrer por todas as causas em aproximadamente 170 mil chineses com idade $\geq 40$ anos acompanhados por dez anos

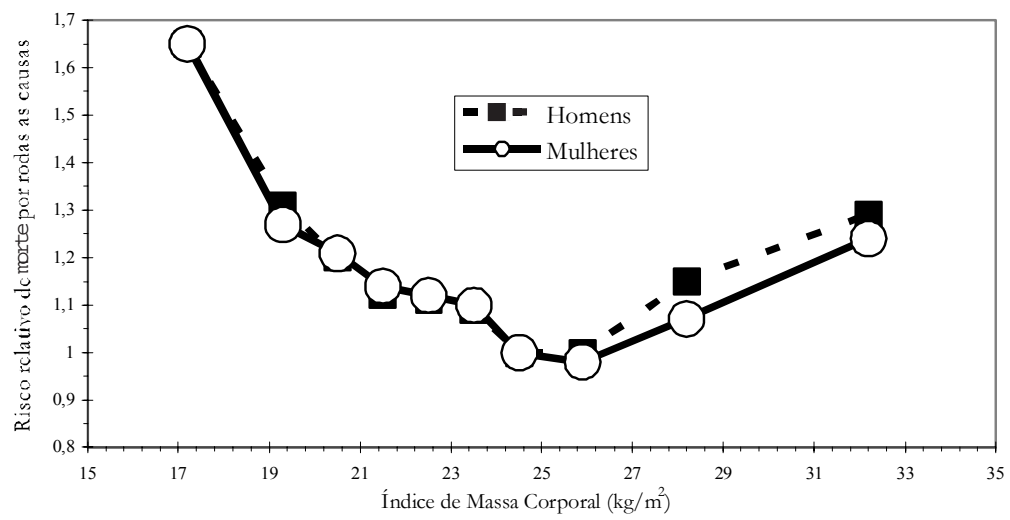

Obs.: Referência: $24<\mathrm{IMC} \leq 25 \mathrm{~kg} / \mathrm{m}^{2}$

Fonte: Desenhado a partir de dados publicados por Gu et al. (2006).

Em 1981, Garrow (1981) sugeriu o uso do IMC como critério para estabelecer a gravidade da obesidade e para o tratamento da obesidade em adultos. Até então, os valores usados eram os de IMC menor do que $20 \mathrm{~kg} / \mathrm{m}^{2}$ para o baixo peso; IMC entre 25 e $30 \mathrm{~kg} / \mathrm{m}^{2}$ para sobrepeso e IMC maior ou igual a $30 \mathrm{~kg} / \mathrm{m}^{2}$ para obesidade, indiscriminadamente para homens e mulheres. Pela sugestão de Garrow continuariam sendo considerados normais os indivíduos com IMC entre 20 a $25 \mathrm{~kg} / \mathrm{m}^{2}$, mas a obesidade seria graduada 
em três níveis, e a conduta variaria de um tratamento conservador (alteração da dieta e aconselhamento de prática de atividade física) para o sobrepeso (IMC entre 25 e $20 \mathrm{~kg} / \mathrm{m}^{2}$ ); medicamentoso, para indivíduos com IMC entre 30 e $40 \mathrm{~kg} / \mathrm{m}^{2}$; e cirúrgico (nos casos de IMC maior ou igual $40 \mathrm{~kg} / \mathrm{m}^{2}$ ). Mais tarde, outros pesquisadores sugeriram o valor de IMC entre 18,5 e $25 \mathrm{~kg} / \mathrm{m}^{2}$ como o valor adequado para o IMC em populações, particularmente após observarem que indivíduos com valores de IMC inferiores a $20 \mathrm{~kg} / \mathrm{m}^{2}$ permaneciam saudáveis e produtivos.

Levando em consideração a literatura acumulada até então, a OMS popularizou o uso do IMC na avaliação nutricional em 1995 criando uma classificação para uso em grupos de indivíduos. Na reunião de consultores sobre obesidade da OMS, realizada em Genebra em junho de 1997, decidiu-se fazer algumas modificações na classificação de 1995. Basicamente, foi incorporada uma categoria de 'pré-obesidade' para a faixa de IMC compreendida entre 25 e $30 \mathrm{~kg} / \mathrm{m}^{2}$ e passouse a chamar de obesidade (em três níveis) para os valores acima de $30 \mathrm{~kg} / \mathrm{m}^{2}$ (Quadro 1). É bom sempre lembrar que a nomenclatura usada - 'baixo peso', 'sobrepeso' e 'obesidade’ - não diz respeito a uma avaliação independente do estado nutricional, mas sim ao risco progressivo de gravidade de doenças crônicas não transmissíveis com o aumento do grau de sobrepeso e obesidade (aumento do IMC após $25 \mathrm{~kg} /$ $\mathrm{m}^{2}$ ) e de algumas outras patologias como enfisema, alguns tipos de câncer com o grau de baixo peso (diminuição do IMC a partir de $18,5 \mathrm{~kg} / \mathrm{m}^{2}$ ).

Em nível populacional, a OMS coloca como meta uma mediana de IMC entre 21 a $23 \mathrm{~kg} / \mathrm{m}^{2}$. Em nível individual, a reco- 
mendação é que cada pessoa mantenha seu IMC entre 18,5 e $24,9 \mathrm{~kg} / \mathrm{m}^{2}$ e que evite ganhar mais do que $5 \mathrm{~kg}$ de massa corporal durante a vida adulta.

Existe uma crescente preocupação com o uso internacional de pontos de corte do IMC para o diagnóstico nutricional. Isso se dá pelo fato de que, apesar da existência de uma boa correlação entre IMC e \%GC, essa relação depende das características étnicas da população em estudo. Ou seja, um valor de $\mathrm{IMC}=25$ representa valores de $\% \mathrm{GC}$ bastante distintos entre várias populações. Apesar dos debates acalorados com grupos a favor e contra, existe uma sugestão de uso de pontos de corte de IMC menores para a população asiática na definição de obesidade. $O$ arrazoado para isso é o fato de aparentemente haver um excesso de fatores de risco para aterosclerose em indivíduos asiáticos com IMC abaixo de 25. Com isso, a Força Tarefa Internacional contra a Obesidade (IOTF, sigla em inglês) sugeriu, para essa população, valores de IMC $=23 \mathrm{~kg} / \mathrm{m}^{2}$, em vez de $25 \mathrm{~kg} / \mathrm{m}^{2}$, como sugerido pela OMS. 
Quadro 1 - Classificação do estado nutricional em adultos segundo o IMC proposto pela OMS em 1995 e 1997, com suas respectivas nomenclaturas

\begin{tabular}{|c|c|c|}
\hline Nomenclatura & \multicolumn{2}{|c|}{$\operatorname{IMC}\left(\mathrm{kg} / \mathrm{m}^{2}\right)$} \\
\hline Baixo peso grau III & \multicolumn{2}{|c|}{$\leq 16,0$} \\
\hline Baixo peso grau II & \multicolumn{2}{|c|}{$16,0-16,9$} \\
\hline Baixo peso grau I & \multicolumn{2}{|c|}{$17,0-18,4$} \\
\hline Adequado & \multicolumn{2}{|c|}{$18,5-24,9$} \\
\hline & OMS (1995) & OMS (1997) \\
\hline Sobrepeso & ------ & $\geq 25$ \\
\hline Sobrepeso grau I (leve) & $25,0-29,9$ & ------- \\
\hline Pré-obesidade & ------ & $25,0-29,9$ \\
\hline Sobrepeso grau II (moderado) & $30,0-39,9$ & ------- \\
\hline Obesidade grau I & ------- & $30,0-34,9$ \\
\hline Obesidade grau II & ------ & $35,0-39,9$ \\
\hline Sobrepeso grau III (grave) & $\geq 40,0$ & ------ \\
\hline Obesidade grau III & ------ & $\geq 40,0$ \\
\hline
\end{tabular}

Um outro fator a se considerar diz respeito ao uso dos pontos de corte de IMC em outros segmentos da população, como os idosos. Existe a sugestão do uso do IMC $=27 \mathrm{~kg} / \mathrm{m}^{2}$ como critério para o sobrepeso em idosos, que é baseada na evidente redução da estatura do idoso. Com a diminuição da estatura observada neste grupo, o denominador da razão seria menor fazendo com que o valor do IMC fosse maior. Como as mudanças na constituição do corpo com envelhecimento são o aumento da quantidade de gordura e a redução na quantidade de mineral ósseo e de água, levando a uma redução da massa magra, os idosos têm uma quantidade de gordura no corpo maior do que a dos jovens para o mesmo valor de IMC. Assim, ao ser 
utilizado um valor de IMC maior, como proposto por alguns, é aceito um valor de \%GC bem maior para a população de idosos já que um mesmo IMC representará um \%GC maior no idoso relativamente à população mais jovem.

A OMS também incorporou a medida do perímetro da cintura (medida feita no ponto médio da distância entre a borda inferior do gradil costal e o ilíaco), após incontestáveis evidências da associação entre o acúmulo de gordura intra-abdominal e as conseqüências metabólicas da obesidade (diabetes, hipercolesterolemia). O risco para essas doenças associadas aumenta com o aumento do valor do perímetro da cintura e o IMC e serve como orientação para o tratamento e o acompanhamento da população. Os pontos de corte para essa medida foram estabelecidos em $102 \mathrm{~cm}$ para os homens e $88 \mathrm{~cm}$ para as mulheres como risco substancialmente aumentado e valores de $94 \mathrm{~cm}$ para homens e $80 \mathrm{~cm}$ para mulheres para o risco aumentado, na ausência do valor do IMC.

Assim, indivíduos adultos com valores de perímetro da cintura entre 94 e $102 \mathrm{~cm}$ (homens) e 80 e $88 \mathrm{~cm}$ (mulheres) devem ser instruídos a controlar o valor de massa corporal e modificar seus estilos de vida com a incorporação de um planejamento de atividade física regular. Já os indivíduos com valores superiores a $102 \mathrm{~cm}$ (homens) e $88 \mathrm{~cm}$ (mulheres), além do controle da massa corporal, devem ser avaliados quanto à possibilidade de existência de outros fatores de risco para doenças crônicas não transmissíveis. Esses pontos de corte estão também sendo revistos e a Federação Internacional de Diabetes (IDF, sigla em inglês) sugeriu, recentemente, valores diferentes do perímetro da cintura considerando-se a etnia para o critério de diagnóstico da síndrome metabólica, como será visto mais à frente. 
A partir da experiência no uso do IMC em adultos, começou-se a pensar em utilizá-lo em crianças e adolescentes, visto as evidências de que existe tendência de crianças e adolescentes com IMC altos permanecerem com valores altos de IMC na idade adulta. O Comitê de Especialistas para o Diagnóstico de Sobrepeso em Adolescentes da Academia Americana de Pediatria e da Associação Médica Americana sugeriu o uso do IMC para o diagnóstico e acompanhamento de adolescentes atendidos em unidades básicas de saúde norte-americanas. O grupo sugeriu o valor do percentil 85 da distribuição do IMC para idade da população americana como critério para risco de sobrepeso. Se o adolescente apresentasse algum outro fator de risco (história familiar de fatores de risco para doenças cardiovasculares, hipertensão arterial ou hipercolesterolemia), o profissional de saúde recomendaria uma avaliação mais detalhada. Para os indivíduos com valores acima do percentil 95, o diagnóstico seria de sobrepeso e a recomendação era para que os adolescentes fossem avaliados mais detalhadamente. $\mathrm{O}$ valor do IMC igual ao percentil 85 de uma distribuição populacional quer dizer que somente $15 \%$ do total dessa população superam tal valor. Da mesma forma, somente $5 \%$ da população apresentam valores superiores ao valor do percentil 95.

A primeira tentativa de diagnosticar sobrepeso em adolescentes foi rapidamente popularizada internacionalmente pela OMS em 1995 com algumas modificações. Para os adolescentes com IMC maior ou igual ao percentil 85 da população americana, o diagnóstico seria 'risco de sobrepeso'. Obesidade só seria diagnosticada se o adolescente com IMC maior ou igual ao valor do percentil 85 tivesse o valor de dobra cutânea tricipital e subescapular maior do que o percentil 90 dessas medidas da 
população de referência americana. A incorporação das medidas de dobra cutânea faria com que se aumentasse a especificidade na identificação dos adolescentes que tivessem, concomitantemente, sobrepeso e excesso de gordura, ou seja, obesidade. Apesar disso, a OMS considerava essa classificação provisória e sugeria que mais dados fossem produzidos para se poder ter uma classificação mais acurada no futuro.

O uso de dados de distribuição de uma medida (ou índice antropométrico) de uma determinada população não expressa necessariamente o estado de saúde da população. Os dados são obtidos em inquéritos populacionais nutricionais e representam a situação da população no momento do inquérito. Essa preocupação é particularmente válida para a fase da adolescência quando o crescimento é bastante rápido e é, em nosso meio, caracterizado pelo fenômeno da tendência secular em estatura, isto é, uma tendência observada durante o século passado de aumento da estatura de uma geração para outra. Isso quer dizer que os filhos tendem a ter uma estatura maior do que a média da estatura dos seus pais. A maior estatura fará com que o valor de massa corporal também seja maior.

Portanto, o valor do IMC referente a um determinado ponto de corte (por exemplo, percentil 85) vai variar entre populações e na mesma população em função das mudanças observadas de aumento na medida da massa corporal e da estatura nas últimas décadas. Na prática, se a população ficar mais gorda, o valor de IMC igual a um percentil poderá ficar maior e assim, o critério para sobrepeso/obesidade seria menos rígido. Esse fato foi documentado na população americana entre 1960-70 e o final da década de 1980 e na população brasileira comparativamente aos dados das décadas de 1970 e 1980. O problema do 
uso de pontos de corte de uma distribuição para se estabelecer critérios para triagem é que, na prática, eles são muitas vezes usados na avaliação individual, inadvertidamente, para fins de se estabelecer um diagnóstico definitivo através das medidas antropométricas. Esses valores deveriam ser usados somente para a triagem dos indivíduos que deveriam ser mais bem avaliados.

Para contornar parte dessas preocupações, pesquisadores, apoiados pelo IOTF, sugeriram em 2000, o uso internacional de curvas de IMC em função da idade, que foram desenvolvidas com base em dados populacionais de várias regiões do mundo (Brasil, Estados Unidos, Holanda, Hong Kong, Reino Unido e Singapura). Tais curvas - chamadas de curvas (ou critério) do IOTF - foram construídas para indicar, a cada idade, o valor de IMC que representaria, dada a tendência da curva, um IMC de $25 \mathrm{~kg} / \mathrm{m}^{2}$ (para o diagnóstico de sobrepeso) ou IMC de $30 \mathrm{~kg} /$ $\mathrm{m}^{2}$ (para o diagnóstico de obesidade) aos 18 anos de idade. Os pontos de corte foram escolhidos pelas evidências da sua aplicação em estudos populacionais em adultos e por terem como objetivo principal fornecer critérios que pudessem dar conta de efeitos biológicos (endpoints), ao invés de serem puramente uma distribuição populacional.

De acordo com essa proposta, se um adolescente tiver um valor de IMC que seja superior à curva que o levaria a esses valores mais tarde na vida, pode-se pensar, com relativo grau de certeza, que ele seja um indivíduo com maior risco de ter sobrepeso ou obesidade na fase adulta e, portanto, deverá ser submetido a tratamento durante a adolescência. Os estudos longitudinais que avaliam o estado nutricional desde a infância até a vida adulta justificam essa estratégia. Por exemplo, no famoso estudo longitudinal sobre fatores de risco para doenças cardiovasculares 
Bogalusa, realizado no estado norte-americano de Lousiana, observou-se que aproximadamente $62 \%$ das crianças que se apresentaram com os maiores valores de IMC (no último quarto, ou seja, na faixa dos $25 \%$ com maiores valores) permaneceram nessa mesma faixa quando chegam à faixa de adultos jovens.

Com relação a crianças até 10 anos de idade, a OMS sugere que valores do índice 'massa corporal para estatura' (ou para comprimento, para crianças até 2 anos de idade) maiores do que dois desvios padrão da mediana de referência da população americana seriam indicativos de sobrepeso. Mais recentemente, o IMC para a idade passou a ser sugerido para o diagnóstico de sobrepeso ou obesidade em crianças menores de 10 anos. Em 2000, o Centro de Controle e Prevenção de Doenças (CDC) norte-americano publicou novas curvas de crescimento para a população americana que incluíam os dados dos cinco estudos nacionais americanos (1963-1994) e, pela primeira vez, gráficos e tabelas com os valores de IMC para a idade. Conscientes da epidemia da obesidade na população americana, houve preocupação de não incorporar dados de indivíduos com idade maior ou igual a 6 anos no mais recente estudo sobre a situação nutricional da população americana, o Terceiro Inquérito Nacional de Saúde e Nutrição Norte-Americano (NHANES III, sigla em inglês para National Health and Nutrition Examination Survey). Tentou-se, assim, evitar a influência do aumento de massa corporal e do IMC que ocorreu entre esse estudo e os estudos anteriores, particularmente para evitar uma mudança para cima dos valores do P85 e P95 do IMC. Da mesma forma, os dados de crianças com muito baixo peso ao nascer $(<1500 \mathrm{~g})$ também não foram incorporados ao banco de dados usado para a construção das novas curvas. As curvas trouxeram como novi- 
dade, pela primeira vez, dados de IMC para idade e que foram estendidos até os 20 anos.

A OMS, em abril de 2006, lançou novas curvas de crescimento de crianças até 5 anos para uso internacional que incorporam, também pela primeira vez, dados de IMC para idade. Segundo a própria OMS, as novas curvas poderão fornecer prevalências de sobrepeso maiores do que as curvas anteriores sugeridas para uso internacional pela OMS (curvas de crescimento da população americana publicadas pelo Centro Nacional de Estatísticas em Saúde (NCHS, sigla em inglês para National Center for Health Statistics)-em 1977, e mesmo as do CDC de 2000 dependendo da idade e gênero.

Existe, portanto, uma tendência atual em usar algum valor de IMC como critério para o diagnóstico do sobrepeso e da obesidade em nível populacional em praticamente todas as faixas etárias. É importante frisar que essas recomendações, na grande maioria, são para uso em estudos populacionais e não para a avaliação clínica individual e não substituem a medição da composição corporal.

\section{Avaliação do percentual de gordura corporal}

A composição corporal pode ser entendida como a expressão do valor de massa corporal em um ou mais dos seus componentes (gordura, massa magra, músculo, osso etc.). Com relação à obesidade, é importante o componente 'massa de gordura corporal' que é tipicamente expressa como o percentual de gordura corporal $(\% \mathrm{GC})$. Entretanto, não existe um critério definitivo para o diagnóstico da obesidade a partir do que realmente conta, ou seja, a quantidade de gordura corporal. Isso se deve, em parte, à falta de grandes estudos relacionando a com- 
posição corporal com os agravos à saúde conforme existem para a relação IMC/morbi-mortalidade, que permitiram o desenvolvimento de pontos de corte de IMC para risco de adoecer em adultos. Os grandes bancos de dados sobre composição corporal vêm de estudos realizados em centros de pesquisas no hemisfério Norte, muitas vezes obtidos em indivíduos jovens. Como esses centros estão, em geral, dentro de laboratórios de avaliação física, a população recrutada para os estudos são jovens universitários com \%GC baixo. Em 1993, as Associações Dietéticas Americana e Canadense sugeriram o valor de 20 a $25 \%$ de gordura corporal como aceitável para mulheres e 15 a $18 \%$ para homens. Essas instituições sugeriram ponto de corte para obesidade baseado no \%GC em 30\% e 25\% para mulheres e homens, respectivamente.

Atualmente, entre os pesquisadores da área de composição corporal e saúde, vem ganhando força a possibilidade de se conhecer o valor do \%GC que estaria relacionado aos valores de IMC reconhecidamente determinantes de risco de adoecer, para se tentar resolver algumas das questões do uso do IMC. Dessa forma, pesquisadores têm tentado calcular, para diversas populações, os valores do \%GC associados ao valor de $\mathrm{IMC}=25 \mathrm{~kg} / \mathrm{m}^{2}$ (sobrepeso) ou IMC $=30 \mathrm{~kg} / \mathrm{m}^{2}$ (obesidade). Usando tal estratégia, um grupo de pesquisadores norteamericanos sugeriu valores de $\% \mathrm{GC}$ a serem utilizados no diagnóstico nutricional de populações afro-americanas ou asiáticas em função do gênero e da idade. Para a população afroamericana ou caucasiana adulta jovem (até 40 anos), os valores de gordura corporal seriam de 39 e $25 \%$ para o diagnóstico da obesidade $\left(\mathrm{IMC}=30 \mathrm{~kg} / \mathrm{m}^{2}\right)$ para mulheres e homens, respectivamente. Para os idosos, esses mesmos valores seriam 42 
e 30\%. Já para a população asiática, os valores seriam, na mesma ordem, 40, 41, 28, e 29\% de gordura corporal.

Outra alternativa seria procurar o valor de IMC a partir de um ponto de corte de \%GC reconhecidamente associado a agravos à saúde. Entretanto, não se conhece, com segurança, o valor de $\% \mathrm{GC}$ a partir do qual se deveria considerar como risco, já que muitos poucos estudos populacionais realizaram medidas de composição corporal. Os estudos com métodos padrão (densitometria corporal, água corporal total ou absorptiometria de Raios-X de dupla energia - DXA), em sua grande parte são realizados em amostras de conveniência e apontam para valores de $15 \%$ e $25 \%$ de gordura corporal como pontos de corte para 'normalidade' para homens e mulheres, respectivamente, já que esses são os valores médios encontrados em tais estudos. No mais recente Inquérito Nacional de Saúde e Nutrição Americano (NHAHES III), estimou-se a composição corporal usando as medidas de dobras cutâneas triciptal e subescapular e recomendou-se uma faixa de valores de \%GC em função da idade e gênero (Quadro 2).

Quadro 2 - Faixa recomendada de percentual de gordura corporal (\%GC) para homens e mulheres americanos

\begin{tabular}{|lll|}
\hline MulHERES & & HoMENS \\
\%GC & Faixa de idade & $\% \mathrm{GC}$ \\
$20-35$ & Adulto jovem & $8-22$ \\
$25-38$ & Meia idade & $10-25$ \\
$25-35$ & Idosos & $10-23$ \\
\hline
\end{tabular}

Fonte: Adaptado de Lohman \& Houtkooper (1997). 
No estudo Bogalusa, em crianças e adolescentes, observouse que valores de \%GC iguais a 25 e 30 para meninos e meninas, respectivamente, também estimados por dobras cutâneas, estavam associados com maior risco de doenças cardiovasculares (pressão arterial, colesterol total e LDL), mesmo após o controle pela idade, raça e gordura no tronco.

Parece consenso, atualmente, que há necessidade de que sejam desenvolvidos métodos mais simples, porém acurados, de avaliação da composição corporal para a avaliação nutricional de populações. Como alternativa, deve-se utilizar o IMC tendo, porém, consciência das várias limitações dessa medida. Quando possível, é importante validar os pontos de corte de IMC em função de medidas de composição corporal em amostras da população em estudo. 


\section{$2 \mid \begin{array}{ll}\text { Agravos à Saúde e Epidemiologia da } \\ \text { Obesidade }\end{array}$}

Segundo o Relatório sobre a Saúde Mundial da OMS de 2002, as doenças crônicas não transmissíveis (diabetes tipo 2, câncer e doenças cardiovasculares) são responsáveis por aproximadamente $60 \%$ da mortalidade mundial e $47 \%$ da carga de doença, e esses números são previstos de aumentar para 73\% e 60\%, respectivamente, pelo ano 2020 .

Dados do Ministério da Saúde brasileiro, em sua publicação de 2005, "Vigilância em Saúde: dados e indicadores selecionados", baseada nos dados de 2003, indicam que a mortalidade proporcional (\% do total de óbitos por causa definida) por doenças cerebrovasculares $(27,3 \%)$ e neoplasias $(13,4 \%)$ ainda são bastante altas. Entretanto, as taxas de mortalidade (por 100 mil, ajustadas para a população de 2000) pelas doenças crônicas não transmissíveis mostram tendências diferentes desde 1980: são declinantes para as doenças cerebrovasculares (50,6 em 2003) e doenças isquêmicas do coração (47,2 em 2003) enquanto são ascendentes, apesar de uma certa estabilização nos últimos dez anos, para o câncer de mama (104,4 em 2003). A taxa de mortalidade por diabetes foi de 21,3 por 100 mil pessoas em 2003. Estima-se que o Brasil gaste 1,5 bilhão de reais por ano com internações hospitalares, consultas médicas e remédios para o tratamento do excesso de massa corporal e doenças associadas (600 milhões vêm do Sistema Único de Saúde - SUS - o equivalente 
a $12 \%$ do orçamento do governo gasto com todas as outras doenças). Esses dados demonstram a importância das doenças crônicas não transmissíveis no país.

O sobrepeso e a obesidade aumentam o risco para todas essas doenças, particularmente a doença coronariana, o acidente vascular cerebral, a osteoartrite e o câncer do endométrio, da mama, da próstata e do cólon. As alterações metabólicas principais associadas à obesidade são: 1) dislipidemia; 2) hipertensão arterial; 3) resistência à insulina e intolerância à glicose; e 4) alterações no sistema de coagulação. Segundo a OMS, aproximadamente $58 \%$ do diabetes, $21 \%$ da doença isquêmica do coração e de 8 a 42\% de certos tipos de câncer poderiam ser atribuídos a IMC maior do que $21 \mathrm{~kg} / \mathrm{m}^{2}$. Há alguns poucos anos, diabetes do tipo 2 não era observado em crianças, mas com o aumento na prevalência da obesidade em crianças e adolescentes já se começa a observar, e em alguns segmentos com uma incidência bastante grande, esse agravo em crianças e adolescentes.

A presença desses fatores de risco é comum nos indivíduos que apresentam doença coronariana antes dos 65 anos de idade. Presume-se que esse quadro tenha como fonte a resistência à ação da insulina e alguns autores chegam a chamar o conjunto desses fatores de risco como 'síndrome de resistência à insulina'. Outros consideram que as alterações metabólicas associadas à obesidade são causadas por um conjunto de alterações e não somente à resistência à insulina e sugerem o uso do termo 'síndrome metabólica' para a condição em que alguns desses fatores de risco estão presentes.

Os mecanismos pelos quais a obesidade predispõe os indivíduos à síndrome metabólica não são totalmente conhecidos, mas sabe-se que a gordura depositada no abdômen tem 
um papel importante no processo. Tanto assim que a Federação Internacional de Diabetes (IDF, sigla em inglês) estabeleceu, recentemente, uma nova definição mundial para a síndrome metabólica. Segundo a nova definição, uma pessoa será considerada como portadora da síndrome quando tiver obesidade central (definida, para a população caucasiana, como perímetro da cintura igual a $94 \mathrm{~cm}$ em homens e $80 \mathrm{~cm}$ em mulheres) e mais duas quaisquer dentre as seguintes condições: 1) triglicérides acima de $150 \mathrm{mg} / \mathrm{dL}(1,7 \mathrm{mmol} / \mathrm{L})$ ou se estiver em tratamento específico para essa dislipidemia; 2) HDL colesterol menor do que $40 \mathrm{mg} / \mathrm{dL}(1,03 \mathrm{mmol} / \mathrm{L})$ no caso de homens e menor do que $50 \mathrm{mg} / \mathrm{dL}(1,29 \mathrm{mmol} / \mathrm{L})$ no caso de mulheres ou se estiver em tratamento para essa condição; 3) hipertensão arterial (pressão arterial sistólica acima de $130 \mathrm{~mm} \mathrm{Hg}$ ou diastólica acima de $85 \mathrm{~mm} \mathrm{Hg}$ ) ou se estiver em tratamento para hipertensão; e 4) glicemia de jejum acima de $100 \mathrm{mg} / \mathrm{dL}$ (5,6 mmol/L) ou se tiver diabetes tipo 2 diagnosticado.

Estima-se que um quarto da população mundial adulta tenha a síndrome metabólica e que 200 milhões tenham diabetes. Desse grupo $80 \%$ irão morrer de doença cardiovascular, o que coloca a síndrome metabólica, em associação com o diabetes, como causa de morbidade e mortalidade muito superior à Aids, embora o problema não seja devidamente reconhecido pela população em geral. Segundo estimativas para a população americana, a obesidade (IMC maior do que $30 \mathrm{~kg} / \mathrm{m}^{2}$ ) estava associada a um excesso de 112 mil mortes para o ano 2000. Estima-se que as condições associadas a dietas não saudáveis e a inatividade física superem, brevemente, o tabagismo como o maior causador de doenças na população americana. 


\section{EpidemiolOGIA DA OBESIDADE}

No mundo

O IOTF mantém um banco de dados sobre a situação do sobrepeso e da obesidade em adultos e crianças de 141 países. Os dados de prevalência do sobrepeso + obesidade (IMC maior do que $25 \mathrm{~kg} / \mathrm{m}^{2}$ ) nos adultos (idade maior ou igual a 18 anos) varia muito entre países, indo desde 5\% na Índia até quase $80 \%$ na Papua Nova Guiné para homens e mulheres (Gráfico 3). Observa-se que a prevalência do excesso de massa corporal pode ser bastante diferente entre homens e mulheres no mesmo país. O Brasil se situa numa escala intermediária, com aproximadamente $40 \%$ e os dados são de 1997, provavelmente da PPV (ver mais à frente).

Gráfico 3 - Prevalência de sobrepeso + obesidade de adultos em vários países do mundo

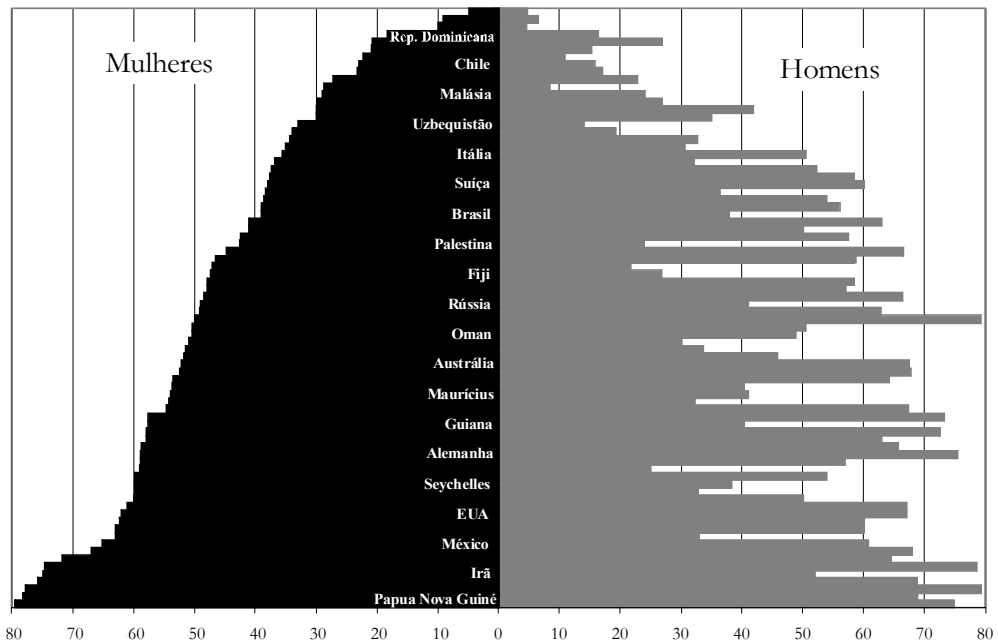

Fonte: Dados disponíveis no site da Força Tarefá Internacional sobre Obesidade (maio de 2006). 
Existem menos informações para crianças e adolescentes (5 a 17 anos de idade) no banco de dados do IOTF e a idade varia muito de país para país (Gráfico 4). Em alguns países existem dados de uma única idade e para outros existem dados de crianças e adolescentes. Os dados do Brasil são de 2002 e de crianças entre 7 e 10 anos. Da mesma forma do que em adultos, não existe associação direta entre a prevalência de sobrepeso/ obesidade nos meninos e meninas.

Gráfico 4 - Prevalência de sobrepeso + obesidade de crianças e adolescentes em vários países do mundo

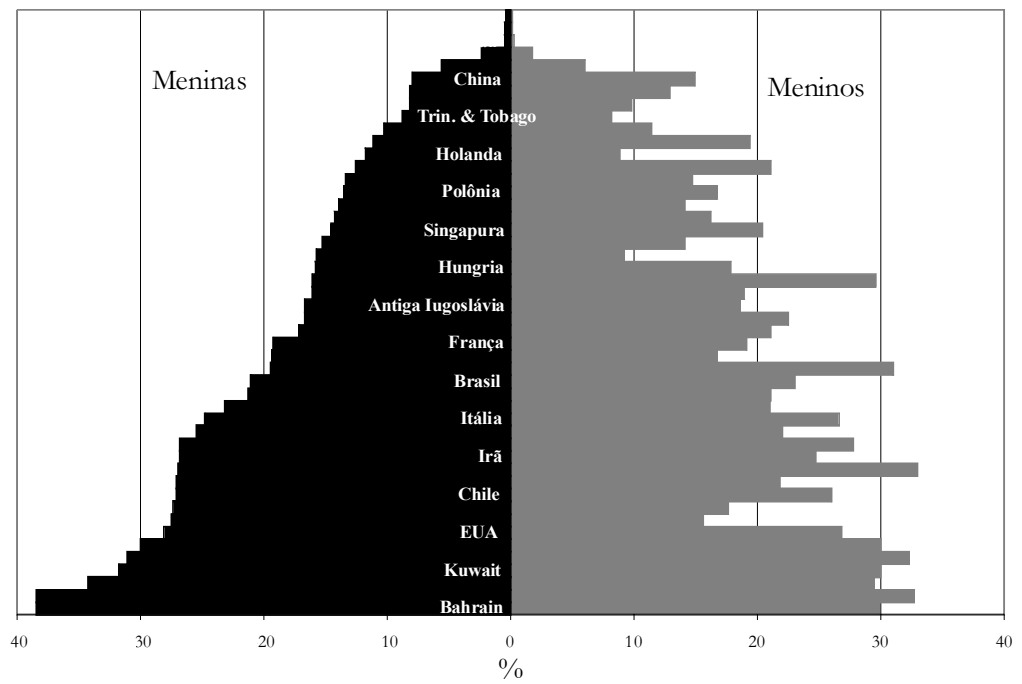

Fonte: Dados disponíveis no site da Força Tarefa Internacional sobre Obesidade (maio de 2006). 


\section{No Brasil}

O Brasil tem conseguido realizar inquéritos antropométricos nacionais ou regionais com intervalos de tempo relativamente curtos, o que permite o acompanhamento da situação nutricional da população. Os dados vêm do Estudo Nacional da Despesa Familiar (Endef) realizado em 1974-1975, da Pesquisa Nacional sobre Saúde e Nutrição (PNSN), realizada em 1989, e da Pesquisa de Orçamentos Familiares (POF), realizada em 20022003 (IBGE, 2006). Existem dados, ainda, da PPV, desenvolvida em 1997, mas que só investigou amostras da população das regiões Nordeste e Sudeste.

Os dados revelam uma redução expressiva na prevalência de desnutrição em crianças e um aumento importante do sobrepeso e da obesidade. Nos países em que este quadro tem ocorrido, comenta-se que os mesmos atravessam um período de 'transição nutricional', em alusão às transformações epidemiológicas ocorridas de prevalências altas de doenças transmissíveis para as de doenças crônicas não transmissíveis. Nesse aspecto, o Brasil aproxima-se mais de um quadro de polarização epidemiológica, já que tanto as prevalências de doenças crônicas não transmissíveis como as de algumas doenças transmissíveis são altas. Da mesma forma, apesar da prevalência relativamente alta de sobrepeso/obesidade encontrada, ainda existe um percentual alto da população brasileira (40\%) com insegurança alimentar como evidenciado na análise da mais recente Pesquisa Nacional por Amostra de Domicílios (Pnad) de 2004.

- Adultos (idade $\geq 20$ anos)

No Brasil como um todo, os dados disponíveis até o momento indicam redução na prevalência de baixo peso 
(IMC $\left.<18,5 \mathrm{~kg} / \mathrm{m}^{2}\right)$ com os valores de 2003 (3\% e 5\% para homens e mulheres, respectivamente), chegando à metade dos valores observados na década de 1970 (Gráfico 5). No mesmo período, a prevalência de sobrepeso dobrou e a de obesidade triplicou nos homens.

Gráfico 5 - Evolução do estado nutricional da população adulta brasileira nos inquéritos nacionais realizados entre 1975 e 2003

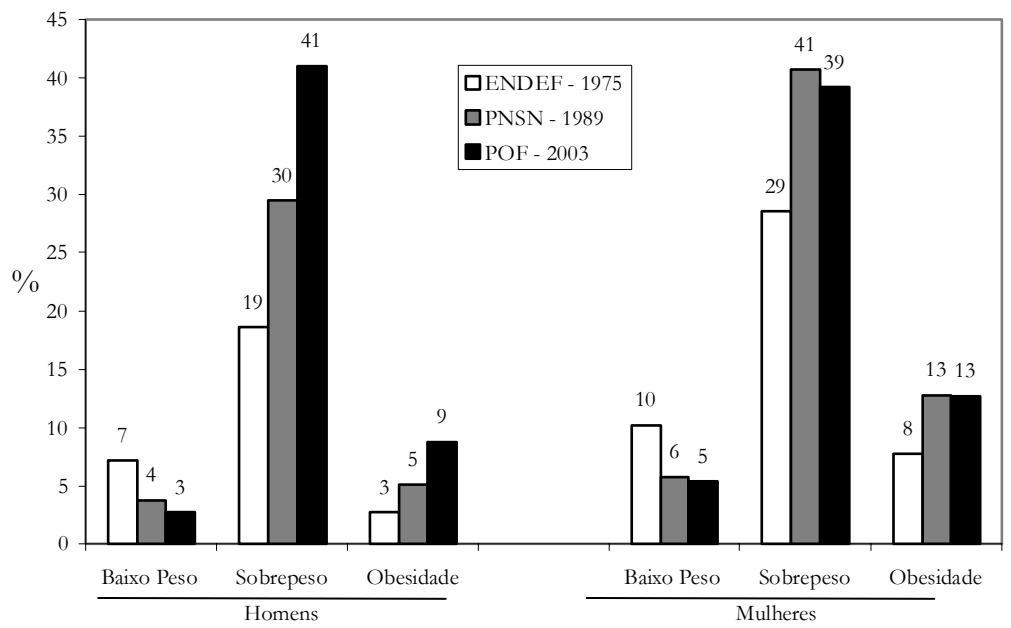

Fonte: Dados publicados pelo IBGE (2004).

A comparação do estado nutricional da população adulta das regiões Nordeste e Sudeste indica que, com exceção da obesidade nas mulheres para quem, aparentemente, existe uma estagnação nos percentuais entre 1989 e 2003 após aumentos substancias entre 1975 e 1989, existe uma clara tendência de aumento nas prevalências de sobrepeso e obesidade (Gráfico 6). Pode-se notar que a prevalência de sobrepeso continua a aumentar em homens e voltou a aumentar em mulheres na pesquisa mais recente. 
A estabilização nas prevalências de obesidade encontrada para mulheres do Sudeste ocorreu também nas regiões Sul e CentroOeste. Já na região Norte o padrão é o mesmo do que o encontrado na região Nordeste, ou seja, aumento na prevalência do sobrepeso e da obesidade.

$\mathrm{O}$ fenômeno observado para as mulheres brasileiras do Sudeste, Sul e Centro-Oeste é raro de se observar no mundo, onde, na grande maioria dos estudos, se encontra aumento progressivo nas prevalências. Tomando-se o Brasil como um todo, o aumento nas prevalências de sobrepeso e obesidade só ocorreu nas mulheres mais pobres, nas famílias com rendimento mensal até meio salário mínimo por pessoa.

Considerando-se a escolaridade, observa-se que há aumento na prevalência de obesidade conforme o aumento no número de anos de estudo completados em cada uma das pesquisas. Comparativamente entre os inquéritos, observa-se que do Endef (1975) para a PPV (1997) o número de homens adultos obesos aumentou cinco vezes para os que não tinham freqüentado escola formal e somente metade disso (2,5 vezes) para os homens que cursaram universidade.

Já para as mulheres adultas, em todos os inquéritos, a relação entre o número de anos de estudo é inversa à prevalência de obesidade, ou seja, a prevalência de obesidade diminui com o aumento do número de anos cursados. Entre as mulheres que não freqüentaram escola, a prevalência de obesidade aumentou aproximadamente três vezes entre o Endef e a PPV. Já para as mulheres que cursaram universidade, o aumento na prevalência da obesidade entre os inquéritos não chegou a dobrar (1,9 vez). 
Gráfico 6 - Evolução do estado nutricional da população adulta do Nordeste e Sudeste nos inquéritos nacionais realizados entre 1975 e 2003

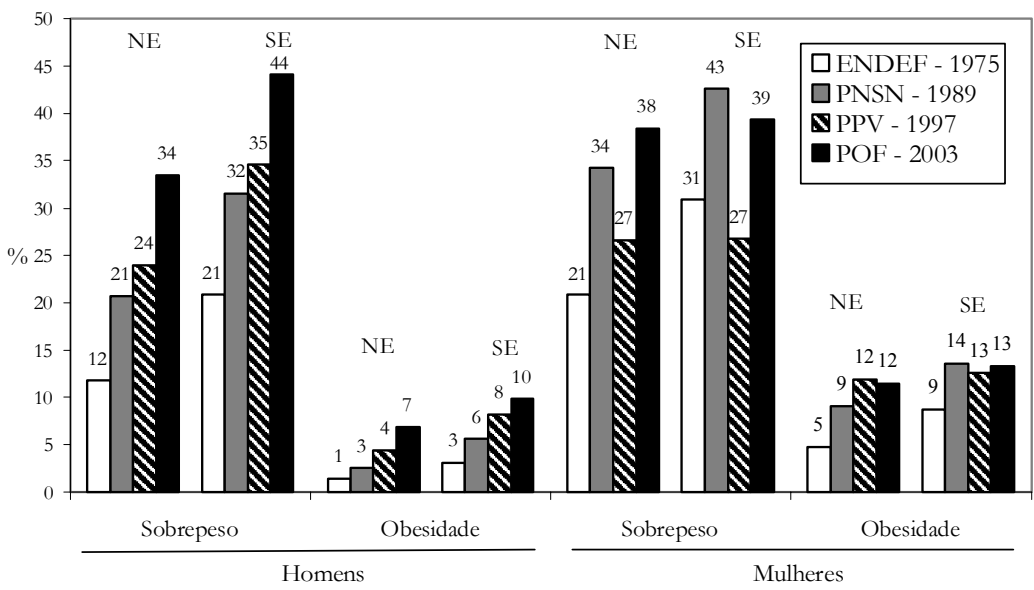

Fonte: Os dados da PPV foram calculados partir dos microdados das pesquisas disponibilizadas pelo IBGE, e os dados dos outros inquéritos foram copiados da publicação do IBGE (e 2004)

Não existe uma explicação definitiva para esses achados, mas, por algum motivo, as mulheres brasileiras adultas das regiões Sul, Sudeste e Centro-Oeste e as mulheres mais ricas e de maior escolaridade pararam (ou diminuíram) o ritmo de aumento na relação massa corporal/estatura. De qualquer modo, os dados indicam que a prevalência de sobrepeso em adultos está em franca ascensão no país. Aproximadamente $50 \%$ da população brasileira, em seu conjunto, apresenta algum grau de excesso de massa corporal (sobrepeso + obesidade) segundo o IMC, o que coloca essa situação como o problema mais sério nutricional da população adulta atualmente no Brasil. 
- Crianças e adolescentes

Os valores de sobrepeso nas crianças e, particularmente, nos adolescentes, vão depender dos critérios usados para sua identificação. Usando as recomendações da OMS para sobrepeso em crianças e risco de sobrepeso para adolescentes, pode-se observar valores ainda relativamente baixos para a população brasileira masculina. Para as adolescentes, parece já ocorrer sobrepeso em um nível preocupante no ano de 1989 (Tabela 1).

Tabela 1 - Prevalência (\%) de sobrepeso em crianças e adolescentes brasileiros no Endef (1975) e na PNSN (1989)

\begin{tabular}{lcccc}
\hline \multirow{2}{*}{$\begin{array}{l}\text { Idade } \\
\text { (Anos) }\end{array}$} & \multicolumn{2}{c}{ Endef } & \multicolumn{2}{c}{ PNSN } \\
\cline { 2 - 5 } $2-3$ & Homens & Mulheres & Homens & Mulheres \\
$3-4$ & 2,4 & 2,8 & 2,9 & 2,9 \\
$4-5$ & 3,7 & 2,4 & 2,1 & 3,2 \\
$5-6$ & 4,0 & 3,6 & 2,6 & 5,0 \\
$6-7$ & 3,0 & 3,0 & 5,0 & 4,9 \\
$7-8$ & 3,8 & 3,9 & 3,4 & 4,1 \\
$8-9$ & 2,8 & 3,4 & 3,4 & 2,1 \\
$9-10$ & 2,6 & 3,3 & 3,7 & 2,0 \\
$10-11$ & 2,6 & 2,3 & 2,7 & 3,7 \\
$11-12$ & 3,4 & 3,5 & 6,5 & 8,4 \\
$12-13$ & 3,9 & 3,5 & 6,6 & 11,2 \\
$13-14$ & 2,5 & 4,3 & 8,5 & 9,4 \\
$14-15$ & 2,2 & 4,2 & 6,2 & 9,8 \\
$15-16$ & 2,4 & 5,0 & 5,6 & 12,9 \\
$16-17$ & 2,0 & 7,7 & 4,9 & 7,5 \\
$17-18$ & 2,0 & 7,1 & 4,4 & 14,4 \\
$18-19$ & 1,6 & 5,4 & 1,9 & 10,0 \\
$19-20$ & 1,9 & 6,6 & 4,0 & 12,9 \\
\hline
\end{tabular}

Fonte: Dados calculados pelo autor. 
Os resultados da avaliação nutricional antropométrica de crianças e adolescentes brasileiros avaliados na mais recente POF (2002-2003) foram disponibilizados em junho de 2006. Infelizmente optou-se por um procedimento diferente do recomendado pela OMS, o que não permite comparações adequadas com dados anteriores. Por possíveis problemas metodológicos não se avaliou o quadro de obesidade em crianças com menos de 10 anos. As estimativas (\%) de sobrepeso e obesidade para adolescentes em função da faixa etária são apresentadas na Tabela 2. Fica evidente que há uma tendência de maiores prevalências de sobrepeso e obesidade no início da adolescência.

Tabela 2 - Prevalência (\%) de sobrepeso e obesidade em adolescentes brasileiros na POF (2002-2003)

\begin{tabular}{llll}
\hline Idade (anos) & Total & Homens & Mulheres \\
\hline \multirow{3}{*}{ Total } & 12,3 & Sobrepeso \\
$10-11$ & 17,7 & 10,4 & 14,4 \\
$12-14$ & 14,3 & 10,9 & 18,5 \\
$15-17$ & 9,4 & 7,1 & 18,4 \\
$18-19$ & 8,3 & 9,2 & 11,9 \\
& & Obesidade & 7,4 \\
Total & 2,3 & 1,8 & 2,9 \\
$10-11$ & 3,7 & 2,4 & 5,0 \\
$12-14$ & 2,4 & 1,7 & 3,2 \\
$15-17$ & 1,8 & 1,5 & 2,2 \\
$18-19$ & 1,6 & 1,8 & 1,4 \\
\hline
\end{tabular}

Fonte: IBGE (2006) 



\section{3, Etiologia}

Praticamente quase a totalidade dos casos de obesidade consiste de um quadro prolongado de balanço energético (BE) positivo (também chamado de obesidade exógena) e não de alterações hormonais ou de endocrinopatias (chamadas de obesidade endógena) como imaginado pela população leiga. Como o BE é a diferença entre a ingestão energética (IE) e o gasto energético (GE), o BE positivo indica que a IE é maior do que o GE. A IE pode ser entendida como a energia metabolizável nos alimentos e inclui a energia absorvida e a não absorvida (celulose e outros carboidratos não absorvíveis que representam 3 a $8 \%$ do total). Em contrapartida, o GE significa a produção total de calor pelo indivíduo, incluindo o calor usado para a manutenção da temperatura corporal, a realização de todos os processos fisiológicos e a evaporação da água.

Diversos autores têm apontado motivos diferentes, relacionados à genética ou ao ambiente, para o surgimento e a manutenção do BE positivo em inúmeros contingentes populacionais. Os estudos que têm sido empreendidos visando a correlacionar aspectos genéticos à ocorrência de obesidade na população não têm sido capazes de evidenciar a interferência destes em mais de um quarto dos obesos. Por isso, acredita-se ainda que o processo de acúmulo excessivo de gordura corporal, na maioria dos casos, é desencadeado por aspectos socioambientais. De 
fato, o aumento na prevalência do sobrepeso/obesidade em muitas partes do mundo é recente, e alterações genéticas não poderiam por si sós explicar o fenômeno.

Um estudo relevante foi realizado em 12 pares de gêmeos monozigóticos (idênticos) que consumiram $1.000 \mathrm{kcal}$ a mais de energia em 6 dias por semana durante 100 dias (totalizando 84 dias de excesso de ingestão ou uma ingestão de $84.000 \mathrm{kcal}$ no período). Durante esse tempo eles ficaram confinados num lugar remoto com os movimentos monitorados continuadamente. Após esse período de relativo sedentarismo, os gêmeos haviam ganhado, em média, $8 \mathrm{~kg}$, sendo aproximadamente $5 \mathrm{~kg}$ de gordura e 3 de massa magra. O IMC aumentou $2,7 \mathrm{~kg} / \mathrm{m}^{2}$ e o percentual de gordura corporal aumentou de $11,3 \%$ no início do confinamento para 17,8\% após os 100 dias.

Entretanto, houve uma grande variação no ganho de massa corporal entre pessoas. Apesar da relativa semelhança entre as mudanças antropométricas e de composição corporal entre os pares de gêmeos, um dos indivíduos chegou a ganhar o dobro de massa corporal em relação ao seu irmão gêmeo. A semelhança de ganho de gordura corporal foi mais pronunciada para a gordura visceral (gordura dentro dos órgãos abdominais). No homem que ganhou menos massa corporal (4,3 kg), somente aproximadamente $40 \%$ do total de energia extra ingerido apareceu como tecido novo. Naquele que mais ganhou massa corporal $(13,3 \mathrm{~kg})$ não houve evidência de perda de energia por qualquer mecanismo. Na média, aproximadamente $29.000 \mathrm{kcal}$ (24\% do excesso de energia consumido) não apareceram na massa corporal. Com este estudo ficou evidente a grande diferença individual no depósito de gordura corporal e de massa magra após o consumo exagerado de energia e a grande dificul- 
dade de se associar a ingestão energética com as modificações antropométricas corporais.

Um dado interessante na questão da interação entre genética e ambiente pode ser observado na comparação entre as características físicas e de saúde nos índios Pima que vivem em cidades no sul do estado do Arizona (Estados Unidos) e em regiões remotas montanhosas no norte do México. Esses índios, cuja separação ocorreu entre 700 e 1.000 anos atrás, têm a mesma herança genética mas vivem hoje em ambientes diametralmente opostos no que diz respeito a estilo de vida e condições sociais. Os índios Pima que vivem nos Estados Unidos já se incorporam ao estilo de vida da sociedade americana onde pouca atividade física é realizada e a alimentação é rica em gordura. Em contrapartida, os índios que vivem no México ainda apresentam estilo de vida tradicional caracterizado por dieta com menos gordura e mais carboidratos complexos e gasto energético maior por se manterem mais ativos. Os índios que vivem nos Estados Unidos apresentam uma das maiores taxas de obesidade e de diabetes tipo 2 vistas em qualquer população no mundo, enquanto os conterrâneos mexicanos não apresentam nem de longe tais características.

Esses achados apontam para a importância do meio ambiente no surgimento da obesidade e das morbidades associadas e ajudaram na formulação de uma associação entre desnutrição no começo da vida e a obesidade mais tarde. Não é raro encontrar, ainda, altas prevalências de desnutrição por déficits de estatura em crianças e obesidade em adultos da mesma região, vivendo sob a mesma condição socioambiental. O pensamento atual é que populações submetidas a restrições nutricionais durante o período fetal ou pós-natal podem estar sob risco aumentado de serem obesas na vida adulta. 
Aparentemente, os períodos críticos para o desenvolvimento da obesidade durante a infância são: a vida fetal; o período compreendido entre a idade de 4 a 6 anos, chamado de rebote de adiposidade (adiposity rebound), no qual o IMC, após a redução inicial depois do nascimento, começa a aumentar e durante a adolescência.

O estudo em jovens holandeses cujas mães foram expostas durante o início da gravidez a um período de escassez durante a Segunda Guerra Mundial evidenciou que a prevalência de sobrepeso foi muito maior do que nos jovens cujas mães não foram expostas à mesma condição. A possível explicação para o fenômeno seria que a privação nutricional ocorreu durante o período de diferenciação do hipotálamo, o que poderia ter acometido os centros reguladores do apetite. Apesar da exposição que ocorreu no final da gestação, período de replicação das células de gordura (adipócitos), a prevalência de sobrepeso foi menor do que nos filhos de mães não expostas.

Como a disponibilidade de alimentos a qualquer hora em grande quantidade se deu recentemente na história da humanidade, pensa-se que um possível mecanismo explicativo para o aparecimento de obesidade num indivíduo desnutrido no começo da vida possa se dar por meio da expressão de genes específicos chamados de 'genes poupadores' (thrifty gens). Por essa hipótese a obesidade resultaria da introdução de um fornecimento contínuo e abundante de alimentos a populações que haviam desenvolvido, ao longo da evolução, a habilidade de armazenar energia de forma eficiente, permitindo, assim, a sobrevivência em períodos de escassez de alimentos.

Existem algumas tentativas de se explicar esse fenômeno, tanto por adaptações que ocorrem não só nos processos fisiológicos 
de manuseio energético quanto nas características comportamentais dos indivíduos.

Aparentemente, os indivíduos que se recuperam de desnutrição tendem a depositar no corpo mais gordura do que proteína, em parte pelo fato de custar menos energia ao organismo para depositar gordura. Da mesma forma, parece que existe um balanço relativamente eficiente entre o que se consome e o que se metaboliza de proteína e carboidrato. Como o organismo precisa sempre de carboidrato para fornecer ao cérebro, uma dieta baixa em carboidrato faz com que se aumente o consumo total de energia numa tentativa para se manter o balanço de carboidrato. Parece também que os indivíduos desnutridos tendem a usar preferencialmente o carboidrato como forma de produzir energia para o organismo. Assim, o indivíduo submetido a restrição nutricional cedo na vida poderá transportar a preferência de metabolizar carboidrato para mais tarde na vida poupando, dessa forma, a gordura armazenada no organismo.

Após somente alguns dias de redução no consumo de energia, o organismo se adapta diminuindo a quantidade de energia gasta durante o repouso. O processo ocorre por mecanismos não totalmente conhecidos mas que passa pela redução de hormônios estimulantes do metabolismo. Da mesma forma, a redução no consumo de energia causa adaptação comportamental como redução da atividade física espontânea, fazendo com que os indivíduos gastem menos energia diariamente. Profissionais que lidam com escolares que vivem em condições socioambientais precárias e, portanto, sob estresse nutricional, costumam declarar que essas crianças são muito ativas. Entretanto, na realidade, elas vivem de explosões curtas de atividades no ambiente social da escola, mas uma análise detalhada do comportamento 
dessas crianças ao longo do dia revela que elas têm muitos períodos de descanso, poupando energia, fazendo com que o gasto energético total diário seja menor do que crianças não submetidas a esses ambientes.

Recentemente, documentou-se uma relação entre o crescimento rápido de crianças recuperadas de desnutrição no começo da vida e o aparecimento de sobrepeso/obesidade na vida adulta. No célebre estudo longitudinal de acompanhamento de nascidos-vivos de Pelotas, Rio Grande do Sul, em 1982, foi comprovada maior prevalência de sobrepeso (66\%) e obesidade (69\%) em 1.076 adolescentes (14-16 anos de vida) que tiveram crescimento rápido de massa corporal entre o nascimento e a idade de 20 meses. Já o crescimento rápido do comprimento esteve associado com a prevalência de sobrepeso (53\% a mais), mas não com a obesidade na adolescência. Esses dados apontam para o que já foi chamado catch-up dilemma (dilema do crescimento rápido de recuperação), para o fenômeno da associação do crescimento rápido no começo da vida e a incidência de doenças não transmissíveis na vida adulta (Victora \& Barros, 2001).

É necessário que os programas de saúde de países em que a desnutrição seja endêmica e que estão submetidas ao processo de transição nutricional enfrentem a necessidade de tratar e recuperar as crianças sob risco de morte por desnutrição no começo da vida, sabendo que essas crianças terão que ser acompanhadas por toda a vida para que não venham a ser uma nova sobrecarga no serviço de saúde ao se tornarem adultos.

Do ponto de vista socioambiental, o quadro de BE positivo pode ocorrer por meio de mudanças no consumo alimentar, com aumento do fornecimento de energia pela dieta, e 
redução da atividade física, configurando o que poderia ser chamado de estilo de vida ocidental contemporâneo. Assim, fica claro o papel dos aspectos socioculturais nesta determinação, formando uma rede de fatores, que ajudam a compreender o atual quadro em evolução em todo o mundo. Nesse cenário, as famílias, particularmente as mães, têm um papel importante, pois compartilham condições socioambientais e culturais semelhantes, fazendo com que possam existir associações diretas em seu estado nutricional.

A análise da relação entre o estado nutricional materno e o de seus filhos na PNSN, de 1989, indicou relação direta entre o estado nutricional materno e sobrepeso nas crianças brasileiras menores de 10 anos de idade. Tomando-se as mães com baixo peso (IMC menor do que $20 \mathrm{~kg} / \mathrm{m}^{2}$ ) como referência, as crianças com sobrepeso tiveram 3,2 vezes maiores chances de terem mãe também com sobrepeso. Sobrepeso nas crianças foi influenciado diretamente: 1) pela escolaridade materna, as mães com doze ou mais séries cursadas tiveram 2,9 vezes mais chances de terem crianças com sobrepeso do que as mães analfabetas; 2) pela renda domiciliar per capita, 3,8 vezes mais chances de sobrepeso nas crianças com maior renda ( $25 \%$ mais ricas) do que as de menor renda (25\% mais pobres); e 3) pelas condições de moradia, 2,7 mais chances de sobrepeso nas crianças de domicílios de boas condições em relação àquelas de piores condições de moradia. Essa relação também foi encontrada para adolescentes brasileiros da região de Pelotas, Rio Grande do Sul, e demonstra a necessidade de intervenção precoce de hábitos, na família, para prevenção da obesidade. 


\section{INGESTÃO ENERGÉTICA}

No que diz respeito ao consumo alimentar da população brasileira, não têm sido realizadas pesquisas de base populacional, em nível nacional, que permitam acompanhar as mudanças efetivamente ocorridas nas últimas décadas. As análises empreendidas a partir de dados sobre os alimentos adquiridos para o consumo das famílias que habitam as regiões metropolitanas nacionais, obtidos nas Pesquisas de Orçamentos Familiares (POFs), realizadas pelo IBGE nos anos de 1988 e 1996, apontam tendência de crescimento na aquisição de alimentos ricos em gordura nas regiões Norte e Nordeste e elevação dos carboidratos simples, acompanhada de redução dos alimentos fontes de carboidratos complexos. Houve, também, aumento na aquisição de carnes, de leite e seus derivados, de açúcar e refrigerantes, e declínio nas compras de leguminosas, hortaliças e frutas.

As mudanças identificadas através das POFs indicam um incremento na aquisição de produtos industrializados e a redução de alimentos in natura por parte das famílias, pois as carnes, especialmente o frango, e os laticínios têm tido uma enorme ampliação na oferta de produtos industrializados no mercado e os refrigerantes constituem, em si, a representação máxima da industrialização na área de alimentos. Na década de 1970, o frango era adquirido recém-abatido nos aviários, ou no máximo embalado inteiro e resfriado nos mercados. Hoje, nos supermercados da maioria das cidades brasileiras, inclusive nas de densidade populacional pequena, é possível adquirir frango resfriado, congelado, temperado, preparado, empanado, recheado, em forma de hambúrguer, almôndega, e inúmeras outras maneiras de preparação, sendo que a maior parte dos produtos 
tem como indicação de preparo, a fritura. Desta forma, o aumento da concentração energética pode se dar através dos recheios, molhos, temperos acrescentados aos produtos e pelo modo de preparo.

O Brasil, hoje, é basicamente um país urbano. Segundo o Censo Demográfico de 2000, havia 168.370 .893 moradores em domicílios particulares permanentes, dos quais somente 31.355.208 (18,6\%) estavam nas regiões rurais. São valores bem diferentes do Censo Demográfico de 1970, quando a população rural compreendia $44,1 \%$ de toda a população brasileira. $\mathrm{O}$ crescimento da urbanização e, portanto, do tamanho das cidades brasileiras, acarreta crescentes problemas na rede de transporte urbano e a conseqüente dificuldade de se realizar refeições em casa, prática comum na década de 1970.

Além disso, a partir de 1980, com a introdução da modalidade de vale-refeição no Programa de Alimentação do Trabalhador (PAT), reduziu-se proporcionalmente a oferta de refeições nos locais de trabalho sob supervisão de profissionais nutricionistas e incentivou-se o consumo de refeições em bares, restaurantes e lanchonetes durante a jornada de trabalho. Esse novo estilo de vida, viver em cidades cada vez maiores e realizar refeições fora do domicílio, muitas das vezes de forma rápida devida à correria da vida moderna, incentivou o aparecimento de redes de restaurantes de alimentação rápida (fastfood). Não é à toa que o Brasil está entre os cinco países que mais cresceram nos últimos anos entre todos os mercados da corporação McDonald's no planeta. Realmente, o crescimento em termos de número de lojas é exponencial desde sua entrada no país em 1979, particularmente a partir dos anos 90 do século passado (Gráfico 7). 
Gráfico 7 - Número de restaurantes McDonald's no Brasil desde sua instalação no país em 1979

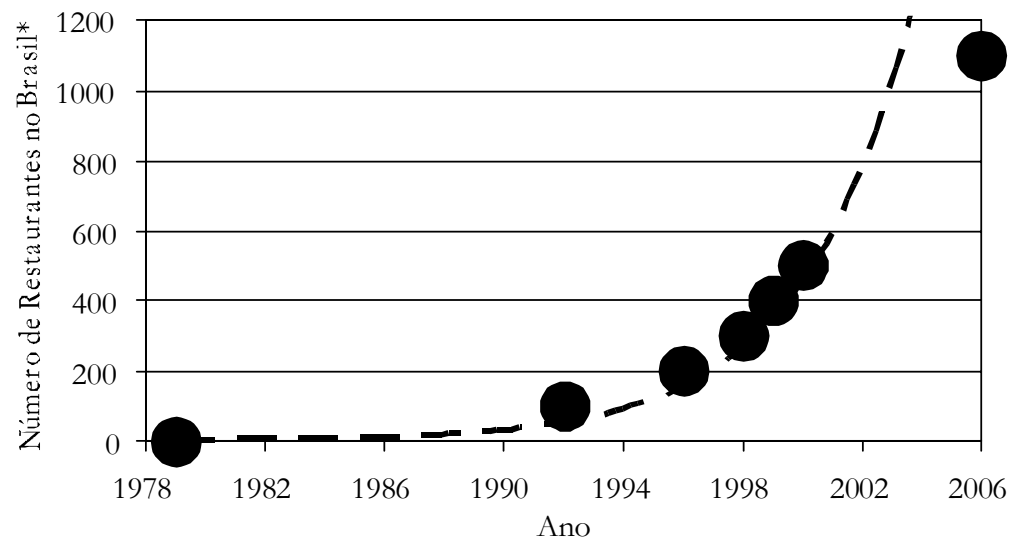

* Dado de 2006 se refere a pontos de venda e incluem restaurantes, quiosques e McCafés.

Fonte: Redesenhado com base em dados publicados por Mendonça \& Anjos (2004).

No documentário Super Size Me, o cineasta Morgan Spurlock se submeteu a uma dieta em que consumiu alimentos vendidos na rede durante trinta dias seguidos em várias lugares dos Estados Unidos enquanto fazia entrevistas para o filme. De acordo com a proposta do cineasta, como expresso no título do documentário, ele aceitou a oferta de incrementar (super size) os lanches todas as vezes que isso ocorreu. Ao final dos trinta dias, o cineasta havia ganho $11 \mathrm{~kg}$, o \%Gc havia aumentado de 11 para $18 \%$, o colesterol sanguíneo havia aumentado 65 unidades alcançando $230 \mathrm{mg} / \mathrm{dl}$. Havia evidências de acúmulo de gordura no fígado, e ele apresentava depressão e se sentia exausto facilmente.

Em estudo recente, de acompanhamento por 15 anos em 3.000 pessoas, os dados mostraram associação positiva forte entre o 
ganho de massa corporal e resistência à insulina (condição presente no diabetes tipo 2) e a freqüência de realização de refeições em restaurantes fast-food. Os indivíduos que se alimentaram mais de duas vezes por semana no período ganharam $4,5 \mathrm{~kg}$ a mais do que os que se alimentaram menos de uma vez por semana. Apesar de esses resultados serem tentadores para se estabelecer uma relação de causa e efeito, deve-se ter cuidado na associação, já que a o aumento da freqüência de consumo de refeições nesse tipo de restaurantes pode simplesmente representar um estilo de vida pouco saudável (preferência por alimentos gordurosos e pouca atividade física), e não uma relação de causa-efeito entre os alimentos vendidos nesses restaurantes e o quadro de obesidade e diabetes.

A introdução de hábitos importados de alimentação rápida, além de comprometer o padrão tradicional alimentar no país, faz com que o próprio ritmo de refeições seja alterado com a substituição de refeições. Essas modificações podem contribuir para a dificuldade na manutenção da massa corporal dentro de padrões considerados saudáveis. Por exemplo, documentou-se, em inquérito de base domiciliar na cidade do Rio de Janeiro, que um padrão dietético que dependia principalmente de feijão com arroz estava associado com risco menor, em adultos, de sobrepeso/obesidade em comparação a uma dieta em que gordura e açúcar eram os principais componentes ou uma dieta de padrão misto na qual não havia um alimento que se destacasse.

A troca de padrões alimentares tradicionais, do tipo feijão com arroz, para um padrão mais contemporâneo, que inclui muita fritura, gordura e açúcar, compromete a saúde da população, podendo aumentar a prevalência de sobrepeso/obesidade. Em muitos restaurantes, atualmente, o feijão com arroz sequer está disponível no cardápio. Por outro lado, pode existir, também, um certo precon- 
ceito da população em pedir, num restaurante, essa combinação seja pelo estigma desse ser um prato popular, seja pela idéia de que esse é um prato para se comer apenas em casa. Em contrapartida, as feijoadas, geralmente nos fins de semana, são populares em muitos centros urbanos, mas essas podem fazer com que o consumo de energia seja muito maior pelos ingredientes mais gordurosos e pela inevitável associação com bebidas alcoólicas.

Um dos programas alimentares mais populares no país contribui, indiretamente, para a manutenção do quadro de sobrepeso/ obesidade: o Programa de Alimentação do Trabalhador (PAT). O programa, instituído em 1976 e regulamentado em 1991, visava a priorizar o atendimento aos trabalhadores de baixa renda, isto é, aqueles que ganhavam até cinco salários mínimos mensais. O PAT tinha (e ainda tem) como objetivo melhorar as condições nutricionais dos trabalhadores, com repercussões positivas para a qualidade de vida, a redução de acidentes de trabalho e o aumento da produtividade, trazendo benefícios, teoricamente, para o trabalhador (melhoria de suas condições nutricionais e de qualidade de vida, aumento de sua capacidade física, aumento de resistência à fadiga, aumento de resistência a doenças e redução de riscos de acidentes de trabalho) e para o empregador (aumento de produtividade, maior integração entre trabalhador e empresa, redução do absenteísmo - atrasos e faltas -, redução da rotatividade, isenção de encargos sociais sobre o valor da alimentação fornecida, incentivo fiscal com dedução de até $4 \%$ no imposto de renda devido). O governo, a princípio, também se beneficiaria do programa indiretamente com a possível melhora das condições de vida da massa trabalhadora pela redução de despesas e investimentos na área da saúde, crescimento da atividade econômica e com a produção de bem-estar social. 
Infelizmente, as avaliações oficiais do programa descrevem somente a quantidade de trabalhadores atendidos por ele (7.924.774) e o número de empresas participantes (73.343). Esses dados, obtidos em 1999, nem estão mais disponibilizados na página da internet do Ministério do Trabalho e Emprego. Uma análise feita sobre o acesso a vale-refeição e estado nutricional de adultos beneficiários do PAT, a partir dos dados da PPV realizada em amostra representativa da população do Nordeste e Sudeste brasileiros em 1997, indica inadequação entre as características do grupo alvo e o acesso a vale-refeição (ou cesta básica), visto que mais indivíduos com sobrepeso do que os com baixo peso e mais pessoas do Sudeste e da camada mais privilegiada recebiam o benefício (Gráfico 8).

Gráfico 8 - Freqüência (\%) de recebimento de vale-refeição ou cesta básica pela população brasileira do NE e SE em função do estado nutricional. Brasil - 1997

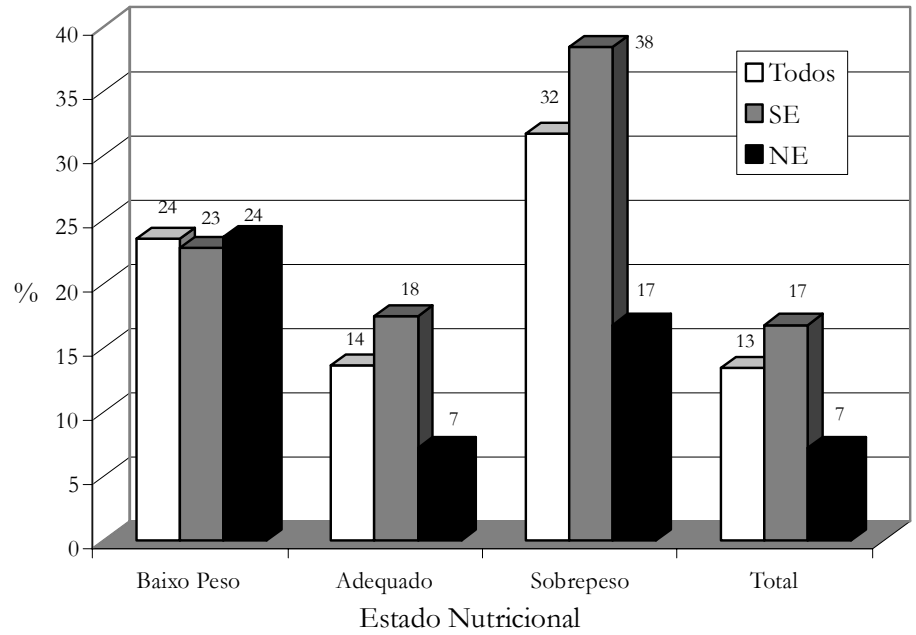

Fonte: Desenhado com base em dados publicados por Burlandy \& Anjos (2001). 
Nas camadas desprivilegiadas da população, redes de assistência, governamentais ou não, permitem a sobrevivência do ponto de vista alimentar por meio da distribuição de cestas básicas ou de restaurantes populares com o preço da refeição subsidiado. Por esses motivos, a mais recente POF (2002-2003) obteve informações sobre o fluxo não monetário e o consumo alimentar fora de casa, além de se tornar uma pesquisa nacional, deixando de ser só metropolitana. Os dados comparativos de energia disponível per capita para a população das regiões metropolitanas obtidos no Endef (1974-5) e nas POFs (1987-8; 1995-6; e 2002-33) indicam aumento entre a década de 1970 (1.700 kcal em 1974-5) e a de 1980 (1.895 kcal em 1987-8) com redução substancial desde então (1.695 kcal em 1995-6 e $1.502 \mathrm{kcal} \mathrm{em}$ 2002-3). Essa tendência é incompatível com o quadro progressivo de aumento do sobrepeso/obesidade na população brasileira no período. Deve-se considerar, entretanto, que, apesar da tentativa da POF mais recente incluir obtenção de alimentos de forma não monetária e de incluir o gasto com o consumo fora de casa, a disponibilidade de energia nessas pesquisas refletem a disponibilidade energética domiciliar e não a disponibilidade global de energia.

Em contrapartida, uma análise do banco de dados da Folha de Balanço Alimentar do Brasil disponibilizado pela Organização das Nações Unidas para a Alimentação e Agricultura (FAO, sigla em inglês) indica que a quantidade de energia por pessoa disponível para consumo humano aumentou substancialmente nas últimas décadas no Brasil, passando de aproximadamente 2.200 para $3.000 \mathrm{kcal} /$ habitante/dia entre 1961 e 1999, ou seja, em torno de $188 \mathrm{kcal}$ diário de acréscimo por década. Essa parece ser uma tendência mais condizente com a realidade nutricional brasileira. 
Em termos do percentual de macronutrientes (gordura, carboidrato e proteína) em relação ao total de energia disponível, a grande modificação se deu no aumento da contribuição da gordura, tanto de origem animal quanto vegetal, com a contribuição da proteína permanecendo estável no período, em torno de 10\%. Portanto, tanto a POF quanto a análise dos dados da Folha de Balanço Alimentar indicam um aumento na disponibilidade (e possível consumo) de gordura pela população brasileira, o que evidencia o aumento na disponibilidade de energia para a população. Devese ter em mente que esses valores dizem respeito à disponibilidade de alimentos para o total da população, sendo impossível, com os presentes dados, estratificá-los por qualquer outra característica sociodemográfica, como macrorregião, idade e gênero.

\section{GASTO ENERGÉTICO}

O gasto energético (GE) diário é composto em sua maior parte pela taxa metabólica basal (TMB), responsável por 50 a 70\% do total, pela ação dinâmica específica dos alimentos (@10\%), e o restante é dado pela atividade física. A TMB é o valor de energia mínima necessário para manter o organismo funcionando em todas as suas funções. É medida com o indivíduo em jejum de pelo menos 12 horas, em repouso num ambiente em que não haja nenhum estímulo por ruído, iluminação ou temperatura. A ação dinâmica específica dos alimentos representa a energia necessária para a digestão, absorção, transporte e armazenamento dos alimentos ingeridos, sendo uma fração pequena do total de energia gasta diariamente e que sofre influência do tipo de alimento ingerido. Já a atividade física pode ser entendida como qualquer movimento corporal produzido pela contração da musculatura esquelética (voluntária) que aumente o gasto energético acima do nível basal, ou seja, 
atividades de lazer, ocupacionais ou cotidianas. Por outro lado, exercício físico é definido como uma atividade física repetida, programada e que tem como objetivo final a obtenção ou melhora de componentes da aptidão física. Portanto, a definição de inatividade física (ou sedentarismo) requer um juízo de valor com relação a níveis (ou padrões) de atividade física, e não simplesmente a realização ou não de exercícios ou prática de esporte.

De qualquer forma, como não parece ter havido tendência de redução da TMB na população, se redução no GE for a real causa para o aumento na prevalência do sobrepeso/obesidade na população, esta deverá advir da redução na atividade física ocupacional ou de lazer e do incremento nas atividades consideradas sedentárias, como assistir à televisão ou trabalhar em computador. $\mathrm{Na}$ verdade, apesar de não haver dados históricos da medida da TMB é de se imaginar que os valores aumentaram já que é evidente o aumento da massa corporal na população. A TMB sofre influência positiva da massa corporal, massa magra (massa corporal - massa de gordura), estatura, tabagismo e hormônios (particularmente os hormônios tiroidianos). Por outro lado, a TMB tende a diminuir com o passar da idade por causa, possivelmente, da diminuição ou alteração da composição da massa magra.

Antes de discutir os padrões de atividade física na população brasileira, deve-se entender como os requerimentos energéticos são estabelecidos, já que eles formam a base para o controle da massa corporal, o balanço energético e a prevenção da obesidade. Essa questão é muito técnica, mas é fundamental para se compreender todo o processo e os problemas associados à sua determinação. Pode ser que o leitor fique frustrado pelo alto grau de tecnicismo, mas é preciso examinar como se faz para estimar os requerimentos energéticos. 


\section{REQUERIMENTOS ENERGÉTICOS}

O requerimento energético é definido como o nível de ingestão energética, a partir dos alimentos, que compensaria o gasto energético para manter a dimensão e a composição corporais e um nível de atividade física compatível com a boa saúde, a longo prazo, além de permitir a realização de atividade física socialmente desejada e economicamente necessária. Os requerimentos energéticos (RE) foram desenvolvidos para serem usados em nível populacional, mas, no cotidiano, também são usados para se determinar as necessidades energéticas em nível individual, o que pode acarretar muitos erros de estimativa.

Como a TMB constitui a maior parte do GE total diário, a medida serve como base para a determinação dos requerimentos energéticos para as populações do mundo. Após se obter a TMB, multiplica-se seu valor pelo nível de atividade física (NAF), valor calculado pela divisão do GE total diário pela TMB. Essa forma de calcular os requerimentos energéticos para adultos foi adotada pela FAO em 1985, abolindo a forma anterior de cálculo que consistia da observação da ingestão energética de uma população saudável. Dessa forma, o requerimento energético é dado como o GE total diário e é um avanço em relação ao método baseado na ingestão energética, já que esta não considera a possibilidade de adaptações que ocorrem na fisiologia energética humana em vários níveis de ingestão alimentar. Formalizada para os adultos na recomendação de 1985, essa forma de estimar os requerimentos energéticos passou a valer para todas as faixas etárias a partir da nova recomendação de 2004. Portanto, o requerimento energético é dado pelo GE total diário como:

Requerimento Energético $=$ GE total diário $=\mathrm{TMB} \times \mathrm{NAF}$ 
Como é necessário se ter um calorímetro para a medição da TMB, que não está disponível na maioria das situações clínicas ou em estudos epidemiológicos, a FAO e a OMS recomendam o uso de equações de predição para sua determinação baseadas nos dados compilados por Schofield (1985). É importante observar que essas equações foram estabelecidas a partir de um número bastante pequeno de indivíduos, principalmente de mulheres e idosos (Quadro 3).

Quadro 3 - Equações de predição da TMB sugeridas para uso internacional

\begin{tabular}{|lll|}
\hline Idade (anos) & $\mathrm{n}$ & TMB $(\mathrm{kcal} / \mathrm{dia})$ \\
\hline \multirow{2}{*}{$18-30$} & \multicolumn{2}{c|}{ Homens } \\
$30-60$ & 2879 & $(15,057 \times \mathrm{MC})+692,2$ \\
$\geq 60$ & 646 & $(11,472 \times \mathrm{MC})+873,1$ \\
& 50 & $(11,711 \times \mathrm{MC})+587,7$ \\
& \multicolumn{3}{c}{ Mulheres } \\
$18-30$ & 829 & $(14,818 \times \mathrm{MC})+486,6$ \\
$30-60$ & 372 & $(8,126 \times \mathrm{MC})+845,6$ \\
$\geq 60$ & 38 & $(9,082 \times \mathrm{MC})+658,5$ \\
\hline
\end{tabular}

Fonte: Adaptado de FAO/WHO/UNU (2004).

Os valores de NAF para os adultos também foram revistos pela FAO (Quadro 4) e são, agora, estabelecidos em faixas segundo as características de atividade e não mais em valores únicos; estes passam a ser únicos para homens e mulheres, enquanto eram distintos na publicação anterior. Foram estabelecidos em função do 'estilo de vida’ em relação à intensidade da atividade física habitual da 
população, ou seja, incorporam todas as atividades realizadas (lazer, transporte, ocupação, etc.) ao invés de somente da atividade física ocupacional, como sugerido na publicação de 1985.

Quadro 4 - Valores do nível de atividade física (NAF) baseados no estilo de vida habitual sugeridos pela FAO/OMS para uso internacional

\begin{tabular}{|ll|}
\hline Categoria de NAF & \multicolumn{1}{c|}{ Valor } \\
\hline Sedentário ou estilo de vida com atividades leves & $1,40-1,69$ \\
Estilo de vida ativo ou moderadamente ativo & $1,70-1,99$ \\
Estilo de vida com atividades pesadas & $2,00-2,40^{*}$ \\
\hline
\end{tabular}

* Valores de NAF > 2,40 são difíceis de manter por um período de tempo longo. Fonte: Adaptado de FAO/WHO/UNU (2004).

Para crianças com mais de um ano de idade e adolescentes, recomenda-se usar, da mesma forma do que para adultos, a TMB x NAF para se estimar o GE total diário e, dessa forma, o requerimento energético. Para facilitar, a publicação da FAO dá uma única equação para meninos e meninas, utilizando os valores de massa corporal (MC) em kg:

Meninos ( $\mathrm{n}=801)$ :

Requerimento energético $(\mathrm{kcal} / \mathrm{dia})=$

$310,2+63,3 *\left(\mathrm{MC}\right.$ em kg) $-0,263^{*}(\mathrm{MC} \text { em kg})^{2}$

Meninas ( $\mathrm{n}=808)$ :

Requerimento energético $(\mathrm{kcal} / \mathrm{dia})=$

$263,4+65,3 *(\mathrm{MC} \mathrm{em} \mathrm{kg})-0,454 *(\mathrm{MC} \mathrm{em} \mathrm{kg})^{2}$ 
Para crianças com menos de um ano de idade, foi dada a opção de se calcular o requerimento energético usando três equações dependendo das características da alimentação das crianças:

AmamentaÇÃo ( $\mathrm{n}=195)$ :

GE total diário $(\mathrm{kcal} / \mathrm{dia})=-152.0+92,8 *(\mathrm{MC} \mathrm{em} \mathrm{kg})$

COM ALIMENTAÇão POR FÓRMULA $(\mathrm{n}=125)$ :

GE total diário $(\mathrm{kcal} / \mathrm{dia})=-29,0+82,6 *(\mathrm{MC} \mathrm{em} \mathrm{kg})$

Todos (amamentação ou alimentação por fórmula) ( $\mathrm{n}=320)$ :

GE total diário $(\mathrm{kcal} / \mathrm{dia})=-99,4+88,6 *(\mathrm{MC}$ em kg$)$

Usando os dados disponíveis da população do Nordeste e Sudeste dos três inquéritos brasileiros (Endef, PNSN e PPV) para representar o Brasil como um todo, pode-se fazer o cálculo da RE e comparar com os valores de energia disponíveis para o país baseados nos dados das Folhas de Balanço Alimentar para os anos específicos dos inquéritos. Fica evidente que a população brasileira está em balanço energético positivo, e que a distância entre a disponibilidade de energia e o requerimento energético da população está crescendo por um aumento muito maior do primeiro do que do segundo (Gráfico 9). 
Gráfico 9 - Evolução na disponibilidade de energia (DE) e dos requerimentos energéticos (RE) para o somatório da população brasileira do NE e SE nos três inquéritos brasileiros

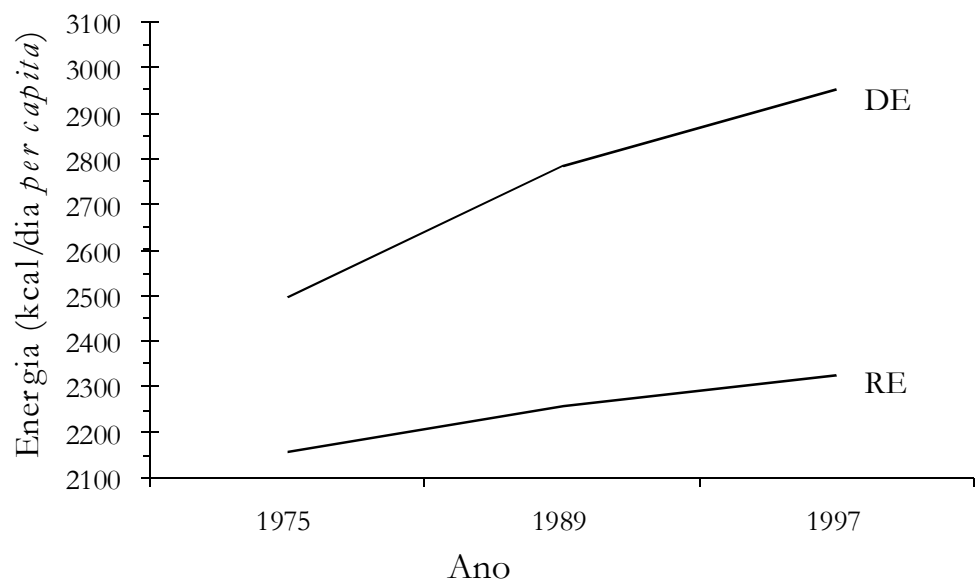

Fonte: Dados calculados pelo autor.

\section{Padrão de Atividade Física NA POPULAÇÃO BRAS I LEIRA}

Os dados sobre o padrão de atividade física da população brasileira são ainda mais escassos do que os de ingestão alimentar. Com relação a uma possível mudança no padrão ocupacional da população, a evolução da distribuição da população brasileira ocupada nos vários setores produtivos, baseada nos dados dos Censos Demográficos desde 1970, indica tendência de diminuição no setor da agricultura e aumento nos setores de comércio tanto em homens quanto em mulheres (Mendonça \& Anjos, 2004). 
Esses dados apontam para uma migração de ocupações de grande demanda de esforço físico (agricultura) para atividades potencialmente com nível de esforço físico mais leve com provável menor GE (comércio). Entretanto, análise dos dados sobre o nível de atividade física ocupacional ( $\mathrm{Nafo}$ ), baseado na ocupação relatada, indica que não houve grandes alterações na distribuição do Nafo na população adulta em pesquisas nacionais realizadas entre 1975 (Endef) e 1989 (PNSN). O Nafo leve (26,6 para $28,8 \%$ ) e o moderado (48,2 para 48,6\%) aumentaram e o pesado reduziu (25,2 para 22,6\%), mas as variações foram muito pequenas. No mesmo período, houve aumento substancial de sobrepeso (IMC maior ou igual a $30 \mathrm{kgm}^{2}$; 22,6 para $34,7 \%$ ) tanto em homens (17,9 para $29,0 \%$ ) quanto em mulheres $(27,4$ para $40,4 \%)$ nesse segmento da população. A prevalência de sobrepeso no período variou de 27,6 para $37,0 \%$ na categoria de Nafo leve e de 12,7 para $18,4 \%$ para o pesado. Essas modificações foram semelhantes em homens e mulheres na direção e na intensidade das tendências, e observáveis em todas as macrorregiões do país. Com base nos resultados pode-se concluir que o Nafo parece não explicar o acentuado aumento na prevalência de sobrepeso na população adulta com ocupação declarada entre 1975 e 1989.

Há pelo menos três possíveis explicações para este fato: 1) aumento da ingestão energética por adulto no período; 2) redução do custo energético das atividades ocupacionais consideradas; 3) modificação no nível de atividade física de lazer (não laboral) da população. Para a primeira possibilidade, apesar de não haver dados de ingestão energética recente em nível nacional, sabe-se que houve aumento substancial na disponibilidade de energia para consumo pela população brasileira nos últimos 
45 anos. No segundo caso, pouco se sabe sobre o custo energético das atividades ocupacionais (e não ocupacionais) nos segmentos da população brasileira. É de se imaginar que tenha havido alguma redução no custo energético das atividades com a introdução de processos de trabalho mais modernos. Entretanto, isso não pode ser generalizado para todo o país e mesmo para diferentes empresas da mesma região.

Informações sobre atividade física de lazer na população são ainda mais limitadas no Brasil. $\mathrm{Na}$ Pesquisa sobre $\mathrm{Pa}$ drões de Vida (PPV) realizada em 1997 em amostra probabilística da população do Nordeste e Sudeste brasileiros, somente $20 \%$ da população indicou a prática de exercício físico ou esporte, havendo um grande diferencial entre homens $(27,3 \%)$ e mulheres $(13,1 \%)$, entre as duas regiões e entre as diversas faixas etárias. O grupo etário mais ativo foi o de 10 a 15 anos de vida tanto para homens quanto para mulheres (Gráfico 10). Há uma dramática redução da prática de esporte ou exercício físico após os 20 anos de idade e os níveis se mantêm em toda a vida adulta. 
Gráfico 10 - Prevalência (\%) de prática de esportes ou exercício físico na população brasileira do NE e SE - PPV (1997)

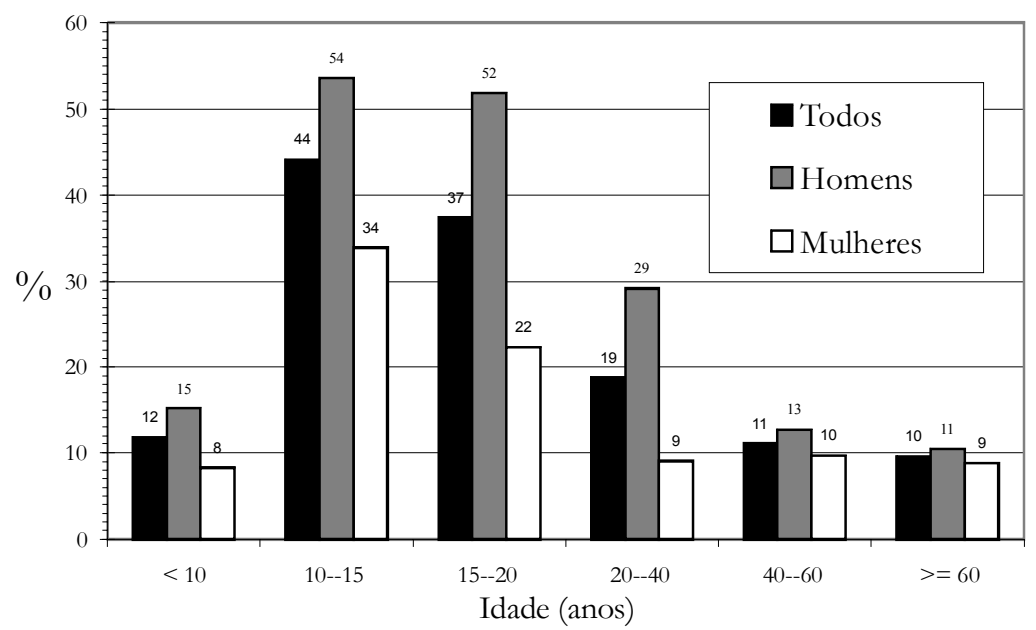

Fonte: Dados calculados pelo autor.

Entre as práticas esportivas ou exercícios físicos relatados destacam-se os esportes coletivos (futebol, vôlei, basquete) para os indivíduos mais jovens, principalmente homens, e a caminhada para os adultos e idosos (Gráfico 11). Em geral, o padrão é semelhante na população das duas regiões, mas com prevalências diferentes para homens jovens nos esportes coletivos e corrida, caminhada e ciclismo para as mulheres de todas as idades. Fica evidente o papel da caminhada como forma de atividade física praticada nos indivíduos adultos, particularmente, após os 40 anos de vida. 
Gráfico 11 - Prevalência (\%) de prática de esportes ou exercício físico, por modalidade, na população brasileira do NE e SE - PPV (1997)

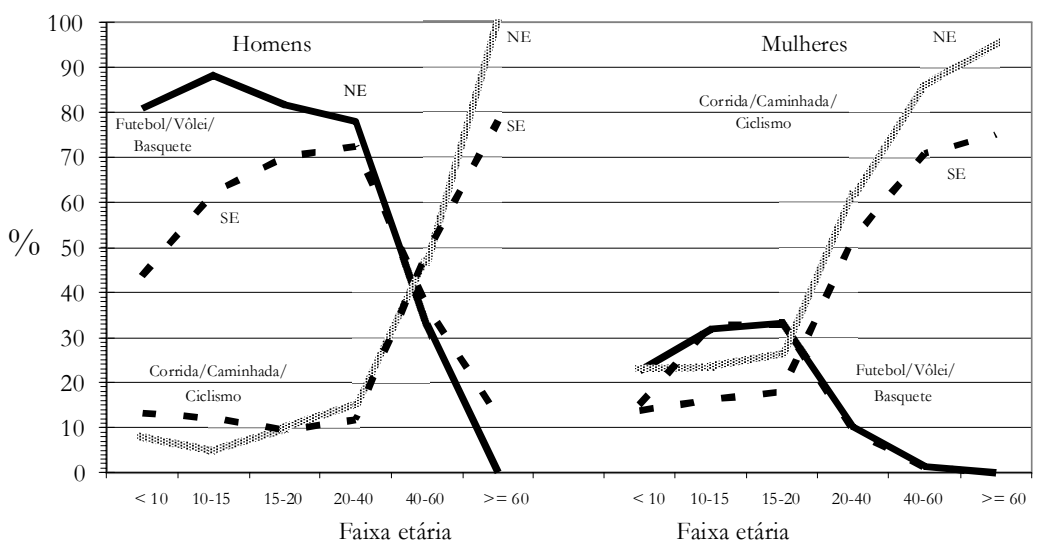

Fonte: Dados calculados pelo autor.

$\mathrm{Na}$ PPV, somente $42,3 \%$ das pessoas relataram ter ocupação. Destes, 29,0\% tinham Nafo leve e 23,6\%, Nafo pesado. As mulheres tinham mais Nafo leve (homens $=22,1$ e mulheres $=40,5 \%$ ) e os homens mais Nafo pesado (homens $=30,5$ e mulheres $=12,0 \%$ ). A diferença mais importante entre regiões foi para o Nafo pesado em mulheres (Nordeste $=36,1$ e Sudeste $=5,6 \%$ ). Entre as pessoas que não praticavam esportes ou exercício físico, $23 \%$ e 49,3\% tinham Nafo pesado e moderado, respectivamente. Ao somar-se pessoas com Nafo pesado aos que disseram que não praticavam exercício físico, o total de ativos sobe para 27,7\% e para $44,2 \%$ se for acrescentado os de Nafo moderado. 
Apesar da limitação na pergunta sobre a prática de esportes ou exercício físico, a PPV foi a primeira pesquisa de base populacional em regiões brasileiras que obteve tal informação. Dados mais recentes, obtidos no Inquérito Domiciliar sobre Comportamentos de Risco e Morbidade Referida de Doenças e Agravos Não Transmissíveis, realizado pelo Instituto Nacional do Câncer (Inca) em amostra da população de 15 capitais e do Distrito Federal em 2004, indicam uma média de indivíduos com idade entre 15 e 69 anos insuficientemente ativos (sedentários + irregularmente ativos) na ordem de 37\% (Gráfico 12) com variação expressiva entre as capitais, sendo João Pessoa a capital com menor população ativa $(55 \%)$ e Belém com a mais ativa (28\%).

Gráfico 12 - Percentual da população brasileira entre 15 e 69 anos insuficientemente ativos em capitais selecionadas e DF

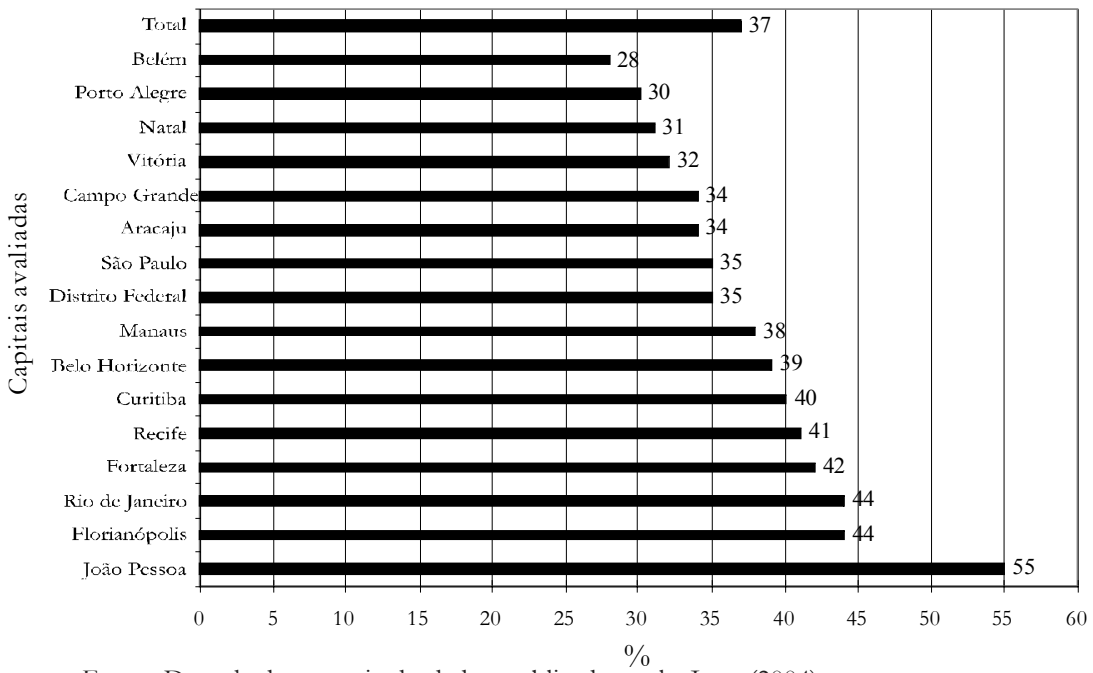

Fonte: Desenhado a partir de dados publicados pelo Inca (2004). 
Os dados da pesquisa do Inca foram obtidos usando-se o Questionário Internacional sobre Atividade Física (Ipaq), que procura obter informações sobre todas as dimensões da prática da atividade física (lazer, trabalho, transporte, etc.). Em países ainda em desenvolvimento, não só a atividade física laboral como também a atividade física associada ao transporte ganha contornos importantes por poder contribuir no total de atividade diária da população. No Brasil, deve-se atentar para esse fato, mas não existem dados disponíveis sobre o padrão de uso de meios de transporte na população em geral. Um dado importante diz respeito à posse de veículos automotores nos domicílios. Nos EUA, somente 5\% dos domicílios 'não' têm automóveis enquanto os dados do mais recente Censo Demográfico indicaram que somente $32,7 \%$ dos domicílios brasileiros têm automóveis (35,3\% na região urbana e 19,1\% na região rural). Comparativamente, havia mais domicílios brasileiros com televisão $(87 \%)$ do que com geladeira $(83,2 \%)$.

Considerando a PPV, que incluiu os dados da população brasileira do Nordeste e do Sudeste, e o inquérito do Inca (15 capitais e o Distrito Federal), representando o Brasil como um todo, os dados parecem indicar que o nível de atividade física da população brasileira não é suficiente para prevenir agravos à saúde, particularmente a obesidade. A recomendação hegemônica atual para a prevenção de doenças na população mundial divulgada por organismos internacionais sugere que todos os indivíduos devam acumular pelo menos 30 minutos de atividade física de intensidade moderada na maioria, preferencialmente todos os dias da semana.

Tal recomendação teve origem na proposta feita pelo Colégio Americano de Medicina Esportiva (ACSM) e pelo Centro 
de Controle e Prevenção de Doenças (CDC) norte-americano à população americana em 1995. Atividade moderada foi definida como aquela em que se gasta em torno de $200 \mathrm{kcal} \mathrm{em} 30$ minutos, o equivalente a uma caminhada entre 4,8 e $6,4 \mathrm{~km} / \mathrm{h}$. Seguindo esse modelo, usa-se com freqüência, como foi feito no inquérito do Inca, o valor de 150 minutos de atividades moderadas por semana (30 minutos feitos 5 vezes por semana) como critério para indicar o indivíduo que não realiza atividade física suficiente. Esse nível de atividade pode ser adequado para a prevenção de doenças crônicas na população em geral, mas não para criar déficit energético e conseqüentemente perder massa corporal. Para esse fim, serão necessárias intensidades ou durações maiores, como será visto mais à frente.

Em suma, os dados sobre ingestão energética e gasto energético parecem indicar que a população brasileira está em balanço energético positivo, fato coerente com o atual perfil antropométrico da população. 


\section{$4 \mid$ Prevenção e Controle}

A OMS estima que mais de 1 bilhão de adultos em todo o mundo sofram com o problema da obesidade, e destes pelo menos 300 milhões apresentem repercussões clínicas dessa condição. Essa prevalência é alarmante e vem crescendo num ritmo acelerado em todo o mundo. Com base nesses dados, a OMS desenvolveu e aprovou a Estratégia Global sobre Dieta, Atividade Física e Saúde, reconhecendo que as doenças crônicas não transmissíveis são responsáveis por aproximadamente 60\% das mortes no mundo e que, desse total, aproximadamente $66 \%$ ocorrem em países em desenvolvimento, quadro causado pelas tendências demográficas e modificações de estilo de vida. A estratégia da OMS inclui, entre outras ações, a necessidade de promoção de estilos de vida que levem em conta uma alimentação saudável e a prática da atividade física capazes de manter o balanço energético na população. Nesse aspecto, o Ministério da Saúde do Brasil tem feito sua parte ao criar Guias de Alimentação Saudável para a população adulta e para crianças.

É importante notar que hoje se dá um peso muito grande ao 'estilo de vida', atribuindo a culpa aos indivíduos pelas suas ações e escolhas na vida. A epidemia da obesidade mundial é um fato relativamente recente e está associada a alterações que ocorreram no mundo, particularmente após a Segunda Guerra Mundial. No Brasil, as decisões sobre o tipo de desenvolvimento econômico e, como conseqüência, a forma de organização da 
sociedade foram feitas no passado e se refletem hoje nos grandes aglomerados humanos nas cidades gigantescas que caracterizam o país.

Existe uma preocupação grande sobre os efeitos que a sociedade urbana (dita moderna) trazem ao ambiente que circundam esses grandes aglomerados urbanos. De fato, tais ambientes são, sob aspectos alimentares e de prática da atividade física, 'obesigênicos', ou seja, facilitadores para a ocorrência de obesidade. Essas características incluem a grande disponibilidade de alimentos com alta densidade energética (além de disponíveis em todos os lugares são também baratos); redução do gasto energético nas atividades cotidianas (automóvel, escada rolante, elevadores, mudanças nos processos de trabalho); aumento das atividades de lazer de menor gasto energético (televisão, computador, jogos de vídeo); e redução das oportunidades para a prática da atividade física regular (lugares públicos seguros, aumento no tempo de trabalho, aumento do tempo nos deslocamentos de e para o trabalho/escola).

Os programas e ações para a prevenção e o controle da obesidade têm sido focados em recomendações para a prática de atividades físicas, tanto no Brasil, quanto em nível internacional. Com exceção da mais recente publicação sobre requerimentos energéticos humanos da FAO, todas as demais são omissas em relação às brutais mudanças na oferta de alimentos, decorrentes do aumento de alimentos industrializados (semipreparados, preparados e congelados) e da expansão dos serviços de alimentação, que adicionaram significados e valores sociais a produtos alimentares de qualidade nutricional duvidosa, com o beneplácito, no Brasil, de uma política econômica de curto prazo, centrada no controle da moeda e no equilíbrio orçamentário. 
Dessa forma, culpabiliza-se o indivíduo por se alimentar mal e por não ser ativo, apesar de serem poucos os lugares seguros para a prática da atividade física. Cabe ressaltar que não é fácil atuar sobre a ingestão de alimentos da população por várias razões. Em geral, as pessoas: 1) são bombardeadas por propaganda sobre alimentação aparentemente saudável, mas muitas vezes enganosas; 2) não comem para satisfazer requerimentos; 3) comem em função da oferta de alimentos; e 4) escolhem os alimentos por motivações financeiras e em função dos valores sociais atribuídos a eles. Tanto é assim, que a indústria de alimentos investe fortunas em propaganda para criar valor social para um alimento. Outro ponto significativo decorre, em parte, do aumento da participação feminina no mercado de trabalho e das mudanças na estrutura familiar: é o aumento das refeições consumidas fora de casa ou feitas em casa com refeições prontas entregues em domicílio.

De qualquer forma, a prevenção da obesidade passa pela manutenção do balanço energético num nível de dimensão e composição corporais saudáveis. O problema é de como isso deve ser operacionalizado para funcionar. Nos indivíduos já obesos é necessário que se construa um déficit energético (balanço energético negativo, ou seja, a ingestão energética menor do que o gasto energético) para que possam consumir as reservas energéticas armazenadas no tecido de gordura do corpo. A experiência internacional é a de que os indivíduos obesos, ou os preocupados com a massa corporal, em determinado momento, se associam a algum programa para a redução da massa (gordura) corporal e conseguem alcançar o objetivo de perder algum excesso; entretanto, mantêm essa situação apenas por algum tempo, em um ou dois eles acabam por readquirir os qui- 
los perdidos. Esse ciclo pode se repetir várias vezes trazendo um estresse psicológico e mesmo financeiro para muitos que eventualmente perdem o controle e desistem de se preocupar com a saúde.

Para tentar entender o processo de escolha de métodos e procedimentos da população obesa para perder quilos em excesso, dois professores americanos desenvolveram, em 1994, o Registro Nacional de Controle de Peso (NWCR, sigla em inglês para National Weight Control Registry) que consiste de um banco de dados de relatos de experiências de indivíduos que perderam massa corporal de uma forma bem-sucedida e haviam conseguido não ganhar os quilos perdidos de volta. Para entrar nesse banco de dados, os indivíduos precisam ter mais de 18 anos de idade e ter perdido pelo menos aproximadamente $13,5 \mathrm{~kg}$ (30 libras) e mantido sua massa corporal por pelo menos um ano. Atualmente, existem mais de 4.000 pessoas registradas no programa que perderam em média mais de $30 \mathrm{~kg}$ (65 libras) e que não ganharam de volta em mais de cinco anos. É importante conhecer as características desse grupo para saber o que realmente funciona no tratamento inicial da obesidade e o que deve ser feito para o controle por um tempo prolongado.

De acordo com análises do banco de dados do NWCR, nenhuma dieta específica se destacou como a de maior sucesso. Estratégias incluíram restrição a certos alimentos, limitação do tamanho das porções, contagem da energia (calorias) e da quantidade de gordura consumidas, uso de refeições líquidas prépreparadas ou dietas de substituição (equivalentes). Para não ganhar os quilos perdidos, a maioria dos sujeitos relatou seguir uma dieta hipoenergética, hipolipídica e com alta quantidade de 
carboidrato (25\% do total energético vindo de gordura, 55\% de carboidrato e $20 \%$ de proteína). Apesar da popularidade atual da dieta que restringe o carboidrato, menos de $1 \%$ dos sujeitos seguia esse tipo de dieta. A maioria relatou fazer entre quatro e cinco refeições diariamente, comer mais em casa do que a maioria dos americanos e comer em restaurantes fast-food uma vez por semana. Uma grande número de indivíduos relatou tomar café da manhã todos os dias, o que, provavelmente, evitou que comessem em excesso mais tarde. Um dado interessante e que contradiz alguns dos guias alimentares disponíveis, é que os indivíduos que tiveram sucesso em manter o peso consumiam dieta com pouca variação em todos os grupos de alimentos (exceto frutas), o que pode indicar que reduzir a variação de alimentos de todos os grupos pode ajudar no consumo de uma dieta de baixa energia e prolongar a manutenção dos quilos perdidos.

Os indivíduos que foram bem-sucedidos em manter o peso também relatam a preocupação em saber o valor da massa corporal com freqüência de pelo menos uma vez por semana, mas muitos mantinham o controle diário. Em média, os indivíduos do NWCR comentam que a atividade física era um componente importante da vida deles, com o gasto energético semanal chegando a aproximadamente 3.000 $\mathrm{kcal}$, sendo que aproximadamente $50 \%$ desse gasto vinha de atividades de intensidade moderada, caminhadas na maioria dos casos, com duração entre 60 e 90 minutos diariamente. Pelo menos para a população americana, esse pode ser o melhor guia a ser sugerido para a população em geral. $\mathrm{Na}$ verdade, o Guia Alimentar para Americanos inclui praticamente todos os aspectos relatados pelos indivíduos bemsucedidos na manutenção da massa corporal. 
O aspecto mais controverso do Guia Alimentar de 2000 dizia respeito à sugestão de "deixar a pirâmide alimentar guiar a escolha alimentar". A pirâmide alimentar, produzida pelo Departamento de Agricultura dos Estados Unidos foi criada na expectativa de que quem a seguisse se tornaria mais saudável, ou seja, a mudança nos hábitos alimentares preveniria o aparecimento de doenças crônicas. A lógica dessa pirâmide, que foi adaptada para a população brasileira e é usada como orientação aos consumidores na rotulagem dos alimentos, baseia-se na idéia de que os alimentos que estão no topo da pirâmide (óleos, gorduras, açúcares e doces) devem ser consumidos em número menor de porções (1 a 2 por dia), e os da base da pirâmide (grupo dos cereais, pães, farinhas, massas, tubérculos e raízes) devem ser consumidos em número maior ( 5 a 9 por dia).

Existem alguns problemas com essa lógica: 1) pela forma como está apresentada, passa-se a impressão de que toda gordura é maléfica e transfere-se para o consumidor o controle de seu comportamento alimentar; 2) a fixação dos tamanhos de porção que não são universais, já que está ocorrendo uma tendência de aumento substancial no número de porções maiores (large size) no mercado a partir de 1980, particularmente nos alimentos industrializados prontos para consumo. Nos EUA, por exemplo, em restaurantes fast-food, não se encontram mais refrigerantes em tamanho pequeno. Mesmo nos supermercados, existe uma grande variabilidade de tamanhos de porção, às vezes a porção de um determinado produto pode ser até sete vezes maior do que a porção definida pelos órgãos responsáveis por sua padronização nos EUA: a Administração de Alimentos e Drogas (FDA, sigla em inglês para Food and Drug Administration) e o Departamento de Agricultura (USDA, sigla 
em inglês para United States Department of Agriculture). Basicamente, essa tendência tem fundamentos econômicos cujas causas são: o aumento na freqüência de refeições realizadas fora de casa, a competição entre produtores de alimentos (levar mais por um custo menor) e o aumento na oferta de produtos pelo mercado (produtos maiores chamam mais atenção). Para o consumidor, tamanho de porção maior poderá significar ingestão energética de até $30 \%$ a mais numa refeição, comparativamente a uma porção menor. Esse fenômeno não pode ser ignorado pelos formuladores de políticas públicas de prevenção e tratamento da obesidade.

No Guia Alimentar americano de 2005, modificou-se a pirâmide, segundo alguns autores, para pior. Não se segue mais a lógica de ter os alimentos em blocos horizontais, e sim em faixas transversais de tamanhos diferentes para representar a proporcionalidade entre os grupos de alimentos. Outras modificações foram a introdução do conceito de moderação, a expectativa de melhora gradual e a variação (cores diferentes para os grupos de alimentos). Entretanto, a grande mudança foi na ênfase dada à atividade física, documentada por um indivíduo subindo a pirâmide, e o desenvolvimento de estratégias para a construção de uma pirâmide personalizada segundo as características individuais numa página da internet.

Críticos ferrenhos da nova pirâmide, pesquisadores da renomada Universidade de Harvard criaram uma pirâmide alternativa, chamada de Pirâmide da Alimentação Saudável, que inclui, em sua base, a recomendação de exercício físico diário e controle de massa corporal. Os vários grupos de alimentos são colocados em blocos da pirâmide, de acordo com a diminuição na freqüência de sugestão de consumo até o pico que apresenta 
as carnes vermelhas e os alimentos refinados cujo consumo deveria ser eventual. Para os pesquisadores, essa lógica é baseada nas melhores evidências científicas de estudos metabólicos, estudos prospectivos e ensaios clínicos para a prevenção das várias doenças crônicas não transmissíveis que evidenciam pelo menos três estratégias gerais: 1) redução da ingestão de gordura saturada e 'trans'; 2) aumento no consumo de ácidos graxos w-3 encontrados em peixes ou suplementos; e 3) consumo de uma dieta rica em frutas, hortaliças, castanhas e cereais integrais.

Segundo os profissionais de Harvard, não se deve colocar a culpa na quantidade de gordura da dieta e sim no controle da energia total consumida. A ênfase no total da gordura da dieta nas últimas duas décadas nos EUA fez com que o percentual da gordura no total de energia consumida tenha diminuído de forma substancial, mas a prevalência de obesidade teve um aumento massivo no mesmo período. Isso indica que o foco da luta para a dieta saudável está errado e maior valor deve ser dado ao total de energia ingerido em vez do total de gordura na dieta.

Os dados sobre atividade física relatados pelos indivíduos bem-sucedidos em perda e manutenção da massa corporal no NWCR, atividades de intensidade moderada com duração entre 60 e 90 minutos diariamente, são exatamente o que vem sendo sugerido por organismos internacionais para o controle da obesidade. O Instituto de Medicina Americano (IOM, em inglês) questionou a premissa de que 30 minutos de atividade física moderada realizada no máximo de dias da semana fosse suficiente para controlar a massa corporal dentro dos limites da normalidade e, também, para obter todos os benefícios à saúde que a atividade física poderia proporcionar. Dessa forma, o IOM (2002) passou a recomendar que a população americana fizesse 
no mínimo 60 minutos de atividade física moderada, correspondente ao valor de nível de NAF maior do que 1,6, valor relacionado a um estilo de vida ativo.

Especificamente para a manutenção da massa corporal dentro dos parâmetros da normalidade, Erlichman et alii (2002) concluíram, após revisão extensa da literatura biomédica, que seria necessário um estilo de vida ativo, correspondente a um NAF de 1,8, o que representaria a realização de atividade intensa, equivalente a uma caminhada de ritmo pesado por 60 a 90 minutos, diariamente. Já o Comitê Conjunto de Consultores da FAO/WHO/UNU (2004) sobre Requerimentos Energéticos Humanos concluiu que seriam necessários 60 minutos de atividade de intensidade moderada para manter a massa corporal saudável e 60 a 90 minutos para prevenir aumento na massa corporal em indivíduos previamente obesos.

Atualmente, o Guia Dietético Americano (U.S. Department of Health and Human Services, 2005) recomenda que o gasto energético seja balanceado com a ingestão energética, associandose alimentação menos energética, com aumento da prática de atividade física, para que a massa corporal seja controlada. Para reduzir o risco de doenças crônicas, o Guia preconiza que adultos façam pelo menos 30 minutos de atividade física de intensidade moderada, preferencialmente todos os dias da semana. No entanto, para a maioria dos indivíduos, a atividade física intensa ou de longa duração, geralmente promove maior benefício à saúde do que a atividade moderada, além de gastar mais energia por unidade de tempo. Dessa forma, para a redução de risco de doenças crônicas, prevenção de ganho de massa corporal e promoção à saúde, recomenda-se aproximadamente 60 minutos de atividade física de intensidade moderada a intensa, 
no maior número de dias da semana. Contudo, cerca de 60 a 90 minutos de atividade moderada por dia, juntamente com uma orientação para controle de ingestão energética, é suficiente para manter a perda de massa corporal, prevenindo o sobrepeso e a obesidade. Assim, a mudança no estilo de vida, tanto na dieta quanto na prática da atividade física, continua sendo a melhor escolha para manutenção ou perda de massa corporal. As recomendações atuais convergem para, no mínimo, 60 minutos diários de atividades de intensidade moderada para o controle da massa corporal.

O Guia Alimentar para a População Brasileira, baseando-se na Estratégia Global sobre Dieta, Atividade Física e Saúde da OMS, recomenda as seguintes ações: 1) manter o equilíbrio energético e o peso saudável; 2) limitar o consumo energético procedente das gorduras, substituir as gorduras saturadas por gorduras insaturadas e eliminar as gorduras 'trans'; 3) aumentar o consumo de frutas, legumes e verduras e de cereais integrais e frutas secas; 4) limitar o consumo de açúcares livres; 5) limitar o consumo de sal (sódio) de toda procedência e consumir sal iodado; 6) manter-se suficientemente ativo durante toda a vida.

Para as ações referentes à alimentação (2 a 5), a operacionalização não é muito complicada. Pode-se argumentar que 'aumentar' ou 'limitar' são verbos que serão conjugados de forma pessoal e cujas mudanças poderão ser difíceis de se acompanhar. De fato, grande ênfase vem sendo dada a formas de intervenção que poderão promover aumento de ingestão de frutas, hortaliças e cereais integrais. Aparentemente, a disponibilidade de frutas e hortaliças era suficiente (400 gramas segundo a IMS) para a população brasileira em 2001. Entretanto, somente $41 \%$ e $30 \%$ de adultos brasileiros relataram consumir diariamente, 
respectivamente, frutas e hortaliças na Pesquisa Mundial de Saúde realizada em 2003 numa amostra representativa da população brasileira.

Tais dados reforçaram a necessidade de iniciativas de promoção do consumo de frutas e hortaliças, particularmente em homens jovens de comunidades rurais com baixa escolaridade e renda. De fato, o Ministério da Saúde do Brasil criou uma proposta para incentivar o consumo de frutas, legumes e verduras, cujo objetivo geral é aumentar o consumo, a produção e a comercialização de alimentos saudáveis na perspectiva de promoção da saúde, do respeito e valorização aos hábitos alimentares culturalmente referenciados, à agricultura familiar, desenvolvimento sustentável e garantia da segurança alimentar e nutricional. Na proposta, fazem-se 'apelos' para a substituição de doces, sorvetes e chocolates por frutas secas; sobremesas por frutas; refrigerantes e bebidas doces por sucos de frutas naturais e lanches noturnos por sopas de legumes, verduras e saladas cruas. Da mesma forma, sugere-se a inclusão de pelo menos uma porção de frutas e hortaliças nas refeições, uma fruta em todas as refeições durante o dia e legumes ou verduras no almoço e no jantar.

As ações 1 e 6 do Guia Alimentar são fundamentais para uma boa prevenção e controle da obesidade. Com relação à prática de atividade física para o controle da massa corporal (item 6), a Força Tarefa Internacional contra a Obesidade e a FAO, em sua publicação sobre recomendações energéticas de 2004, aconselham que os indivíduos gastem 1,75 vez a sua taxa metabólica basal (TMB) como forma de manter a massa corporal saudável. Esse valor é extremamente alto para ser conseguido pela população em geral. Tomando como base valores 
de gasto energético de atividades como múltiplos da TMB, pode-se modelar algumas situações. Por exemplo, se um indivíduo dorme oito horas por dia (1 vez a TMB) e trabalha durante oito horas com uma atividade física ocupacional leve (1,7 vez a TMB), para alcançar um valor final diário de GE de 1,75 vez a TMB, ele poderia: 1) ficar o restante do dia (oito horas) realizando atividade física moderada (2,55 vezes a TMB), bem superior à atividade ocupacional; 2) ficar relaxado durante o lazer (1,4 vez a TMB), mas para isso precisaria fazer, durante uma hora, atividade extremamente pesada (10,6 vezes a TMB), praticamente impossível para a população em geral e mais ainda para a população obesa; ou 3) realizar atividade moderada durante 30 minutos (4 vezes a TMB), como recomendado internacionalmente para a prevenção de doenças, o que faria com que ele precisasse ficar as outras sete horas e meia fazendo atividade a uma intensidade entre leve e moderada (2,45 a TMB), bem superior a que foi feita durante a ocupação. Dessa forma, é praticamente impossível que os indivíduos obesos alcancem o nível de atividade para construir um balanço energético para a redução ou manutenção da massa corporal através da atividade física isoladamente. Entretanto, tem-se dado extrema ênfase na promoção de uma vida ativa para o controle da massa corporal.

Para se saber se o indivíduo está em balanço energético (item 1 do Guia Alimentar para a População Brasileira), utiliza-se o valor da ingestão energética (IE), obtida por questionário ou por diário, e estima-se o requerimento energético (RE), que é baseado no valor da TMB e do NAF segundo recomendações da FAO e da OMS. Essas instituições recomendam o uso de equações de predição para TMB, já que a aparelhagem para sua medição (calorímetro) ainda é cara para ser usada rotineiramente 
em situações clínicas. O problema é que existem evidências de que as equações sugeridas superestimam a TMB em diversas populações do mundo, particularmente as que vivem em regiões tropicais. Uma análise de 16 estudos encontrados na literatura sobre a validação das equações de predição indica que em sua maioria (dez estudos) a TMB foi superestimada pelas equações em comparação ao valor de TMB medido (Wahrlich \& Anjos, 2001). Essa característica ocorreu tanto para grupos de indivíduos residentes em regiões tropicais quanto temperadas, como América do Norte e Europa, sendo que para essas populações os estudos de validação são mais escassos. Os valores percentuais de superestimativa observados variaram entre $2,2 \mathrm{e}$ $13,5 \%$, e nos estudos que avaliaram tanto homens quanto mulheres, as mulheres tenderam a ter valores percentuais de superestimativa inferiores quando comparados aos dos homens de mesma faixa etária.

É importante frisar que esses são valores médios de superestimativa e que, mesmo nestes estudos, as equações podem ser adequadas ou subestimarem a TMB em alguns indivíduos. Por exemplo, em estudo realizado em 50 universitárias do curso de Nutrição da Universidade Federal Fluminense (UFF), foi encontrada superestimativa de TMB (média de 14\%) em 80\% das mulheres jovens e subestimativa (média de 7,4\%) nas outras dez mulheres. Numa amostra representativa de adultos residentes em Niterói, estado do Rio de Janeiro, foi observado que o valor de TMB estimado pelas equações de predição recomendadas para uso internacional era superior aos valores medidos de TMB em $22 \%$ nos homens e $19,4 \%$ nas mulheres.

A capacidade de se estimar adequadamente a TMB é particularmente difícil nos obesos porque eles têm mais gordura cor- 
poral. Como a gordura corporal não contribui significativamente para o metabolismo e como as equações de predição usam as informações de massa corporal para seu cálculo, os valores de TMB são mais superestimados do que para os indivíduos com menor quantidade de gordura corporal.

O outro fator da equação para se determinar o requerimento energético é o valor do nível de atividade física (NAF) que foi desenvolvido inicialmente a partir de dados teóricos de custos energéticos de atividade (Recomendações Energéticas de 1985). Entretanto, atualmente é baseado no gasto energético de populações usando a técnica da água duplamente marcada (Recomendações Energéticas de 2005). Uma alternativa a esse método extremamente caro é a realização da sua estimação pelas características de atividade da população. A realização dessa análise nos dados do Endef (1975) identificou que os valores de NAF para a população brasileira feminina com mais de 18 anos eram maiores do que necessários para os requerimentos energéticos, o que poderia levar as mulheres à obesidade caso fosse seguido, causando o inverso (desnutrição) para os adolescentes (tanto homens quanto mulheres) ao não prever energia para as atividades ocupacionais que os adolescentes brasileiros faziam. O problema foi reconhecido, por isso, para determinar os novos requerimentos energéticos, sugeriu-se não mais um valor fixo de NAF e sim uma faixa, permitindo, dessa forma, que se possam escolher os valores mais adequados para uma determinada população ou seus segmentos.

A literatura médica está cheia de exemplos de estudos realizados com pessoas obesas nos quais, de modo geral, se observa que elas não ingerem mais energia do que as não obesas e, muitas vezes, aparecem com balanço energético negativo (IE $<\mathrm{RE})$. 
Existem três possíveis explicações para o fenômeno: 1) os indivíduos obesos, quando perguntados sobre a alimentação ou quando eles mesmos mantêm um diário do que ingerem, podem ter uma tendência em relatar menos alimentos do que realmente consumiram, ou então, como eles terão de anotar o que foi ingerido, eles modificam o hábito alimentar ingerindo menos energia do que normalmente ingeririam; 2) o RE é superdimensionado para os indivíduos obesos (superestimativa de TMB e NAF); ou 3) os indivíduos dizem que realizam mais atividades (e portanto um NAF maior) do que de fato fazem, e com isso o valor de NAF usado poderia ser maior levando a um requerimento maior. Além disso, os métodos de conversão de alimentos (tabelas de composição química de alimentos) e atividades (tabelas de custo energético de atividades) em energia não são totalmente confiáveis.

Uma avaliação de 36 alunas do curso de Nutrição da UFF exemplifica essas questões. As alunas mantiveram um diário de atividades e de ingestão alimentar por um período de 24 horas. Os dados dos diários foram convertidos em energia ingerida (IE) e gasto energético (para se estabelecer o RE). Nessas mesmas alunas foi possível medir o gasto energético no mesmo período pelo método da freqüência cardíaca. Os dados mostraram que a IE foi de $1.746,7 \mathrm{kcal}$ e o GE medido foi de $1.522,6 \mathrm{kcal}$ indicando BE positivo $(224,1 \mathrm{Kcal})$, o que era esperado para uma amostra de mulheres com \%GC médio relativamente alto (28\%). Entretanto, o GE estimado (TMB x NAF, uma aproximação do RE) foi de 2036,6 kcal, fazendo supor que as universitárias estavam, em média, ingerindo aproximadamente $500 \mathrm{kcal}$ a menos do que deveriam. Dessa forma, a interpretação dos dados e a conduta serão 
diferentes se o GE for medido e não estimado para estabelecer o RE. Como o GE não é medido na prática clínica, devese ter muito cuidado ao se calcular as RE para a população, particularmente num quadro evidente de transição nutricional em que a população brasileira atravessa atualmente.

Especificamente para os indivíduos adultos obesos (IMC $\geq$ $30 \mathrm{~kg} / \mathrm{m}^{2}$ ou indivíduos com perímetro da cintura dentro de valores de risco), parece razoável pensar numa dieta que construa um BE negativo progressivo e que possa ser bem aceito por eles. Para uma perda de 500 a 900 gramas de massa corporal por semana, faixa considerada como segura, a ingestão energética deverá ser reduzida de 500 a 1.000 kcal por dia do nível de ingestão atual e devem-se associar ações modificadoras de hábitos alimentares e de prática de atividade física, conforme o caso. Dietas muito restritivas devem ser evitadas. Em geral, dietas com 1.000 a $1.200 \mathrm{kcal}$ por dia podem ser usadas para a maioria das mulheres, dietas com 1.200 a $1.600 \mathrm{kcal}$ por dia podem ser apropriadas para homens ou mulheres com massa corporal maior do que $75 \mathrm{~kg}$ ou que se exercitem. De forma geral, as mudanças a longo prazo são mais prováveis de serem bem-sucedidas quando as preferências individuais são consideradas e quando os indivíduos são instruídos quanto à composição dos alimentos, rotulagem, preparação e tamanhos de porção.

Em geral, as pessoas só aceitarão mudanças radicais em seus estilos de vida, caso ocorra algo grave como o diagnóstico de alguma patologia ou a ocorrência de um evento agudo. Por isso, talvez uma alternativa mais aceitável seja a construção de metas a serem avaliadas de tempos em tempos. É fundamental dar opções para o indivíduo e instruí-lo em como se preparar para os imprevistos que podem ocorrer dentro do planejamento. Ter 
uma fruta sempre por perto pode ajudar na escolha de qual alimento comer por motivos emocionais, por exemplo. Devemse também fazer mudanças de estilo de vida gradativamente para que a pessoa consiga ver o que está e o que não está funcionando. Dessa forma, o profissional de saúde sempre terá opções a serem tentadas, evitando que o indivíduo desista de tudo e ache que não tem mais jeito.

Para os indivíduos com mais de 18 anos e que tenham IMC $>40 \mathrm{~kg} / \mathrm{m}^{2}$ ou valores mais baixos desde que apresentem comorbidades e que tenham tentado o controle não cirúrgico com um profissional especializado, existe sempre a alternativa extrema da cirurgia para redução do estômago ou criação de um bypass do estômago. Para muitos, a cirurgia é o método mais eficaz e talvez até mais barato para reduzir a massa corporal em indivíduos com obesidade grave. Cada vez mais o método é utilizado e recentemente foi incluído no SUS, que realizou, no ano de 2003, 1.813 procedimentos no país.

Com o aumento na prevalência do sobrepeso/obesidade em crianças e adolescentes, é fundamental que se planejem medidas específicas de ação para esses segmentos da população. As sugestões envolvem o desenvolvimento de mensagens sofisticadas de marketing para as crianças e os jovens, com o intuito de desenvolver atitudes comportamentais saudáveis, reduzir o tempo dedicado a assistir à televisão, aumentar a atividade física e promover a amamentação. No primeiro caso é necessário o envolvimento de educadores em parceria com os diversos meios de comunicação mídias (rádio, TV, imprensa escrita) para a introdução e disseminação de estilos de vida saudáveis que compreendem os hábitos alimentares e a manutenção de uma vida ativa. A proposta de redução do tempo de TV assistido por 
crianças se traduz na possível redução à exposição da propaganda da indústria de alimentos. Esse é um mercado bastante forte que consegue exercer uma grande pressão sobre os políticos. Para se ter uma idéia, estima-se que 33 bilhões de dólares sejam usados em propaganda de alimentos nos EUA.

No segundo semestre de 2005, a rede de fast-food McDonald's investiu R $\$ 10$ milhões somente em comunicação, embalagem e desenvolvimento de um único novo sanduíche chamado de Big Tasty. Testado inicialmente, de forma sintomática, no mercado de Brasília, a promessa era que o sanduíche poderia saciar a fome até dos mais famintos, já que ele tinha um hambúrguer de 150 gramas, duas fatias de pão com gergelim, duas rodelas de tomate, alface, cebola, um molho especial e três fatias de queijo emental, que, pela primeira vez, entrava no cardápio de um sanduíche da rede. A introdução deste novo sanduíche no mercado brasileiro visava a atender àquele consumidor que compra um Big Mac e o complementa com o hambúrguer ou cheeseburguer. Usando a mesma desculpa, a rede Hardee's lançou, ao final de 2004 nos EUA, um sanduíche que, de forma apropriada, era chamado de Monster Thickburguer (hambúrguer monstruosamente espesso), continha $1.420 \mathrm{kcal}$ e 107 gramas de gordura. Como a competição entre as redes de lanchonetes de fast-food é bastante grande nos EUA, é de se esperar que outras novidades venham por aí no futuro próximo.

Além de propagandas específicas voltadas para as crianças durante todo o ano, a cada quatro anos, a própria rede lança cardápios especiais durante a Copa do Mundo no Brasil, com o objetivo de manter a marca em evidência durante o período, buscando associar seu nome ao evento, paixão do povo brasileiro, e simultaneamente a um dos mais importantes eventos es- 
portivos no nível global. É sintomático que a própria seleção brasileira de futebol tenha sido patrocinada por uma marca de refrigerantes de guaraná (Antarctica) e que a Coca-Cola fosse uma das patrocinadoras globais do evento.

Nas residências de muitas famílias, a televisão permanece ligada durante todo o dia. Em um estudo realizado pela Fundação Kaiser Permanente, em 2005, em uma amostra de famílias americanas, foi evidenciado que em 51\% dos domicílios a TV estava sempre ligada, em 63\% dos domicílios ela estava ligada durante as refeições e em $53 \%$ dos lares não havia regras impostas às crianças para assistir à televisão. As famílias poderiam usar a TV como uma forma de mudança de comportamento, ao criar regras para assistir aos programas, baseando-se mais em conteúdo da programação do que em tempo, com o objetivo de criar valores de gerenciamento do tempo para atividades mais lúdicas e formativas.

Alguns parlamentares já propuseram leis específicas sobre a propaganda comercial de alimentos na TV brasileira. O projeto de lei do Senado SF PLS 25, de 24/2/2003, do Senador Tião Viana, ainda em tramitação, prevê que a propaganda comercial de alimentos só seja permitida entre 21 horas e 6 horas e que seja proibido: 1) empregar imperativos que induzam diretamente ao consumo; 2) sugerir o consumo exagerado; 3) atribuir ao produto propriedades nutricionais ou outras não comprovadas cientificamente; e 4) incluir a participação de crianças ou adolescentes. Especificamente sobre a obesidade, a proposta PL6080 do Deputado Júnior Beltrão, de 19/10/2005, também ainda em tramitação na Câmara, prevê a proibição da propaganda comercial, inclusive merchandising, de bebidas e alimentos potencialmente causadores de obesidade, nas emissoras de rádio e televisão nos horários entre 6 horas e 21 horas. 
Essa legislação é particularmente importante no Brasil onde aproximadamente 60\% das propagandas entre 1998 e $2000 \mathrm{em}$ todas as redes de TV do país constituíam-se de alimentos com gordura e açúcar, o inverso do previsto na pirâmide alimentar, por exemplo. A propaganda de alimentos foi a de maior prevalência (aproximadamente 22\% do total) seguida da de redes de lojas ao varejo (aproximadamente $16 \%$ ) e de produtos de beleza $(11 \%)$ durante os dias da semana, e de bebidas alcoólicas $(12 \%)$ aos sábados. Estima-se que em 1999, tenham sido gastos no Brasil, aproximadamente, 11 bilhões de dólares em propaganda, sendo que a metade foi para a TV.

Em setembro de 2005 foi nomeado, na Agência Nacional de Vigilância Sanitária (Anvisa), um grupo de trabalho, com representantes do governo, do Congresso, de instituições de defesa do consumidor, da indústria de alimentos, da Sociedade de Pediatria e do Conselho Federal de Nutrição, com a incumbência de apresentar uma proposta de Resolução de Diretoria Colegiada ( $\mathrm{RDC} \mathrm{n}^{\circ} 73$ ) para o controle de propaganda, publicidade, promoção e informação de alimentos cujo objetivo, prático, é proteger o público infantil em relação ao aumento das doenças crônicas não transmissíveis.

Ciente das tentativas de produção de legislação para o setor, o Conar propôs novas normas éticas para a publicidade de anúncios de alimentos e refrigerantes e de produtos destinados a crianças e adolescentes. As normas, aprovadas pelo Conselho Superior em 23/3/2006, fixam o dia $1^{\circ}$ de setembro de 2006 como prazo para que as propagandas sejam adequadas à atualização do Código Brasileiro de Auto-Regulamentação Publicitária. Prevê-se que não se vinculem frases como "peça para a mamãe comprar..." ou "faça como eu, use..." com o objetivo de elimi- 
nar ou reduzir o consumo. Sobre esse aspecto, a nova redação do Anexo $\mathrm{H}$ do Código é taxativa ao prever que, quando o produto for destinado à criança, sua publicidade deverá, ainda,

abster-se de qualquer estímulo imperativo de compra ou consumo, especialmente se apresentado por autoridade familiar, escolar, médica, esportiva, cultural ou pública, bem como por personagens que os interpretem, salvo em campanhas educativas, de cunho institucional, que promovam hábitos alimentares saudáveis.

Um outro ponto importante diz respeito à sugestão de "abster-se de apresentar qualquer produto como substituto das refeições básicas (desjejum, almoço e jantar), a menos que tal indicação esteja embasada em responsável opinião médica ou nutricional, reconhecida pela autoridade sanitária”.

Se efetivamente forem postas em prática, essas normas poderão contribuir para a melhora dos hábitos alimentares em geral e da oferta de alimentos nas escolas, em particular. Várias tentativas já ocorreram no Brasil com vistas a reduzir a oferta de determinados alimentos nas cantinas e nos arredores do ambiente escolar. Por exemplo, o Decreto n. 21.217 de 1/04/2002, do Prefeito César Maia, proibia, no âmbito das unidades escolares da rede municipal de ensino do Rio de Janeiro, adquirir, confeccionar, distribuir e vender bala, doce à base de goma, goma de mascar, pirulito, caramelo, refresco de pó industrializado, refrigerante, qualquer alimento manipulado na escola ou em ambiente não credenciado para confecção de preparações alimentícias, bebida alcoólica, alimentos com mais de $3 \mathrm{~g}$ de gordura em $100 \mathrm{kcal}$ do produto, com mais de 160 mg de sódio em 100 kcal do produto e alimentos que contivessem corantes, conservantes ou antioxidantes artificiais (observada a rotulagem nutri- 
cional disponível nas embalagens), alimentos sem rotulagem, composição nutricional e prazo de validade. Além disso o decreto também proibia a divulgação de propaganda de quaisquer produtos nas dependências da escola. Essa ação se baseia, em parte, nos resultados de uma pesquisa realizada, em 1999, numa amostra representativa de escolares (4 a 18 anos) do município do Rio de Janeiro que revelaram prevalências preocupantes de sobrepeso (18\% das meninas e $14 \%$ dos meninos) e obesidade em aproximadamente $5 \%$ dos escolares.

Em maio de 2006, a fundação do ex-presidente americano Bill Clinton, Aliança para uma Geração mais Saudável (Alliance for a Healthier Generation), em associação com a Associação Americana do Coração (American Heart Association) conseguiram um acordo inédito. Os maiores fabricantes de refrigerantes americanos concordaram em estabelecer guias para limitar o tamanho das porções e reduzir o total de energia disponível para as crianças nas escolas americanas. Segundo esses guias, somente bebidas nutritivas e de baixa quantidade de energia podem ser vendidas nas escolas a partir de então.

Outras ações são importantes, como a introdução de aspectos da alimentação saudável no conteúdo de várias matérias que fazem parte do currículo escolar. Nesse aspecto, a escola tem ainda um papel importante no incentivo da prática da atividade física não só ao ensinar e desenvolver habilidades motoras que serão úteis por toda a vida, mas também ao ensinar os aspectos benéficos da vida ativa na saúde e do bem-estar das pessoas.

Apesar de se reconhecer a necessidade de combater de uma forma vigorosa os interesses comerciais que propagandeiam coisas prejudiciais à saúde, o que foi bem-sucedido 
com relação ao tabagismo, por exemplo, é necessário desenvolver e implementar estratégias globais que sejam condizentes com a vida moderna e que possam oferecer para toda a população acesso aos comportamentos saudáveis independente da condição social.

A última sugestão para o controle de sobrepeso/obesidade em crianças é a amamentação, que é, sem sombra de dúvidas, a mais apropriada forma de alimentação para crianças até um ano de idade além de reduzir a incidência de doenças agudas. Nos EUA existe uma propensão em recomendar a amamentação como uma forma de prevenir a obesidade na vida adulta, baseando-se em algumas revisões que indicaram que crianças que eram amamentadas tinham menor chance de se tornarem obesas mais tarde na vida. Entretanto, análises das coortes de nascidos-vivos em Pelotas, Rio Grande do Sul, em 1982 e 1993 parecem indicar que não há associação entre a prática da amamentação e sua duração na prevalência do sobrepeso aos 4 anos (coorte de 1993) e aos 18 anos (coorte de 1982). Revisões recentes da literatura também demonstram pouca influência da amamentação na prevenção da obesidade na vida adulta. A discrepância entre esses achados pode ser causada pela não consideração da condição socioeconômica dos indivíduos. Nos países desenvolvidos, parece existir associação positiva entre a amamentação e a alta renda e instrução dos pais. Da mesma forma, o tempo de duração da amamentação pode estar associado a essas variáveis sociais. Portanto, os estudos que mostram associação entre a amamentação e a prevenção da obesidade e não controlam as condições socioeconômicas devem ser interpretados com cautela.

As estratégias para prevenir a obesidade e promover mudanças no estilo de vida incluem ações de muitos atores, muitas das vezes 
com enfrentamento de interesses poderosos ou corporativos, que vão desde os governos em todos os níveis (taxando alimentos com baixo valor nutricional e subsidiando os alimentos saudáveis, garantindo áreas para a prática da atividade física, controle da oferta de alimentos em escolas), passando pela imprensa (disseminando informações sobre hábitos saudáveis), a indústria alimentícia (rotulagem dos alimentos) até os profissionais de saúde e educação. 


\section{RefERÊNCIAS}

BURLANDY, L. \& ANJOS L. A. Acesso a vale-refeição e estado nutricional de adultos beneficiários do Programa de Alimentação do Trabalhador no Nordeste e Sudeste do Brasil, 1997. Cadernos de Saúde Pública, 17(6): 1457-64, 2001.

$\mathrm{FAO} / \mathrm{WHO} / \mathrm{UNU}$ (Food and Agriculture Organization)/World Health Organization/United Nations University. Human energy requirements. Food and Nutrition Technical Report Series 1. Roma: FAO, 2004.

GARROW, J. S. Treat Obesity Seriously: a clinical manual. Edinburgh: Churchill Livingstone, 1981.

GU, D. et al. Body weight and mortality among men and women in China. JAMA, 295(7): 776-83, 2006.

GURRICI, S. et al. Relationship between body fat and body mass index: differences between Indonesians and Dutch Caucasians. European Journal of Clinical Nutrition, 52(11): 779-83, 1998.

IBGE (Fundação Instituto Brasileiro de Geografia e Estatística). Pesquisa de Orçamentos Familiares 2002-2003. Análise da Disponibilidade Domiciliar de Alimentos e do Estado Nutricional no Brasil. Rio de Janeiro: IBGE, 2004.

IBGE (Fundação Instituto Brasileiro de Geografia e Estatística). Pesquisa de Orçamentos Familiares 2002-2003. Antropometria e Análise do Estado Nutricional de Crianças e Adolescents no Brasil. Rio de Janeiro: IBGE, 2006. 
INCA (Instituto Nacional do Câncer). Inquérito Domiciliar sobre Comportamentos de Risco e Morbidade Referida de Doenças e Agravos Não Transmissiveis. Rio de Janeiro: Inca, 2004.

IOM (Institute of Medicine of the National Academies). Dietary reference intakes for energy, carbohydrate, fiber, fat, fatty acids, protein, and amino acids. Part 1. Washington: The National Academy Press, 2002.

KEYS, A. et al. Indices of relative weight and obesity. Journal of Chronic Diseases, 25: 329-43, 1972.

LOHMAN, T. G. \& HOUTKOOPER, L. Going SB: body fat measurement goes high-tech - not all are created equal. ACSM's Health \& Fitness, 1(1): 30-5, 1997.

MENDONÇA, C. P. \& ANJOS, L. A. Aspectos das práticas alimentares e da atividade física como determinantes do crescimento do sobrepeso/obesidade no Brasil. Cadernos de Saúde Pública, 20(3): 698-709, 2004.

SCHOFIELD, W. N. Predicting basal metabolic rate, new standards and review of previous work. Human Nutrition: Clinical Nutrition, 39C (suppl. 1): 5-41, 1985.

UNITED STATES. Department of Health and Human Services. Dietary Guidelines for Americans, 2005. Disponível em: <www.health.gov/ dietayguidelines/dga2005/document>. Acesso em: 5 abr. 2005.

VICTORA, C. G. \& BARROS, F. C. Commentary: the catch-up dilemma - relevance of Leitch's 'low-high' pig to child growth in developing countries. International Journal of Epidemiology, 30: 217-20, 2001.

WAHRLICH, V. \& ANJOS, L. A. Aspectos históricos e metodológicos da medição e estimativa da taxa metabólica basal: uma revisão da literatura. Cadernos de Saúde Pública, 17(4): 801-17, 2001. 


\section{Sugestões dE LeItURAS}

Muitas das fontes usadas para a produção deste livro estão acessíveis pela internet. No site da Organização Mundial da Saúde (www.who.int/), podem-se obter diversas publicações gratuitas em formato PDF. Algumas não estão disponíveis na sua integridade. Pelo menos cinco publicações foram muito úteis para este livro.

Inicialmente, a publicação Physical Status: the use and interpretation of Anthropometry, WHO Technical Report, Series 854, de 1995, serve como base técnico-científica para o uso da antropometria na avaliação nutricional de populações. Ela demonstra todo o processo de desenvolvimento das classificações usadas e o arrazoado para as medidas empregadas. Especificamente com relação à obesidade, a publicação intitulada Obesity: preventing and managing the global epidemic, WHO Technical Report, Series 894, de 2000, traz todo o arcabouço metodológico para a nova classificação do estado nutricional baseada no índice de massa corporal e a introdução da medição do perímetro da cintura. As publicações Diet, Nutrition, and the Prevention of Chronic Diseases, de 2003, e Preventing Chronic Diseases: a vital investment, de 2005, trazem com detalhes as associações entre a obesidade e as doenças crônicas não transmissíveis, suas prevalências, a projeção do impacto dessas na mortalidade mundial e as várias estratégias de prevenção a serem tomadas pelos vários governos no mundo. É fundamental a leitura do documento intitulado Global Strategy 
on Diet, Physical Activity and Health, aprovado pela $57^{\mathrm{a}}$ Assembléia da OMS em 2004 e que trata dos esforços necessários que todos os povos têm de fazer para enfrentar a epidemia de obesidade. Pode-se também ter acesso a toda a documentação sobre as novas curvas de crescimento de crianças até 5 anos de idade para ser usada internacionalmente que incluem pela primeira vez as curvas de IMC para a idade.

No site da Organização das Nações Unidas para a Alimentação e Agricultura (www.fao.org/), é possível acessar a publicação mais recente (2005) sobre os requerimentos energéticos humanos (Human Energy Requirements. Food and Nutrition Technical Report, Series 1). É lá que também se podem obter os dados das Folhas de Balanço Alimentar (Food Balance Sheets) de todos os países membros, inclusive o Brasil.

No site da Força Tarefa Internacional contra a Obesidade (www.iotf.org/), há diversas publicações em PDF que tratam de vários aspectos da obesidade, além de descrever as últimas notícias sobre a obesidade e os mais recentes achados científicos. Além disso, o site fornece possibilidade de links para diversos sites institucionais no mundo inteiro. É lá que se podem obter informações sobre a prevalência de sobrepeso e obesidade no mundo inteiro.

O site do Centro de Controle e Prevenção de Doenças norteamericano (Centers for Disease Control and Prevention www.cdc.gov/) tem várias publicações sobre obesidade e sua relação com atividade física. No link com o Centro Nacional de Estatísticas em Saúde (National Center for Health Statistics), pode-se ter acesso a toda a documentação sobre as mais novas curvas de crescimento para a população americana divulgadas em 2000 (www.cdc.gov/growthcharts/). 
No site da Fundação Instituto Brasileiro de Geografia e Estatística (www.ibge.gov.br/), encontram-se as principais informações sobre todos os Censos Censitários realizados no país. As análises preliminares sobre a disponibilidade de alimentos e o estado nutricional da população brasileira, bem como os dados do estado nutricional de adolescentes na mais recente Pesquisa de Orçamentos Familiares (POF) realizada entre 2002 e 2003 estão ali disponíveis.

Da mesma forma os resultados iniciais do Inquérito Domiciliar sobre Comportamentos de Risco e Morbidade Referida de Doenças e Agravos Não Transmissíveis, realizado pelo Instituto Nacional do Câncer (Inca), estão disponíveis em seu site (www.inca.gov.br/).

O Ministério da Saúde do Brasil (www.saude.gov.br/) também disponibiliza diversas publicações sobre nutrição, doenças crônicas, mortalidade e alimentação saudável, particularmente os Guias de Alimentação Saudável para a população adulta e para crianças (http://dtr2004.saude.gov.br/nutricao/documentos/ guia_alimentar_conteudo.pdf).

A nova pirâmide alimentar americana individualizada pode ser acessada pela internet (www.mypyramid.gov/) com a possibilidade de se construir um diário para acompanhamento da dieta e da atividade física, com cálculo de necessidades energéticas, gasto energético diário total e análise de dieta.

No Registro Nacional de Controle de Peso Americano (www.nwcr.ws/), é possível ter acesso a várias histórias de sucesso na perda e manutenção da massa corporal.

As novas normas para publicidade de alimentos, refrigerantes aprovadas pelo Conselho Nacional de Auto-regulamentação Publicitária (Conar) podem ser acessadas na página da entidade (www.conar.org.br). 
Formato: $12,5 \times 18 \mathrm{~cm}$

Tipologia: Letter Gothic e Garamond

Papel: Pólen Bold $70 \mathrm{~g} / \mathrm{m}^{2}$ (miolo)

Cartão Supremo $250 \mathrm{~g} / \mathrm{m}^{2}$ (capa)

Fotolitos: Laser vegetal (miolo)

Engenho e Arte Editoração Gráfica Ltda. (capa)

Impressão e acabamento: Imprinta Express Ltda.

Rio de Janeiro, julho de 2006

Não encontrando nossos títulos em livrarias, contactar a EDITORA FIOCRUZ:

Av. Brasil, 4036 - térreo - sala 112 - Manguinhos

21040-361 - Rio de Janeiro - RJ

Tel.: (21) 3882-9039 e 3882-9041

Telefax: (21) 3882-9006

http://www.fiocruz.br/editora

e-mail: editora@fiocruz.br 

